\title{
Mechanical properties, thermal conductivity, and modeling of boron nitride-based polymer composites: A review
}

\author{
T. E. Mokoena ${ }^{1}$, S. I. Magagula ${ }^{2}$, M. J. Mochane ${ }^{1 *}$, T. C. Mokhena ${ }^{3}$ \\ ${ }^{1}$ Department of Life Sciences, Central University of Technology, Free State, Private Bag X20539, 9300 Bloemfontein, \\ South Africa \\ ${ }^{2}$ SUN ACE South Africa (PTY) LTD, 12 Innes Road, Jet Park 1459, Johannesburg, South Africa \\ ${ }^{3}$ Nanotechnology Innovation Centre, Advanced Materials Division, Mintek, Randburg, South Africa
}

Received 1 May 2021; accepted in revised form 19 July 2021

\begin{abstract}
In the past, polymer materials have been used in electronic devices; however, the major drawback with polymers is their low thermal conductivity, i.e., $0.1-0.5 \mathrm{~W} /(\mathrm{m} \cdot \mathrm{K})$. Hence, researchers came up with the idea of incorporating conductive fillers into the polymer matrix in order to increase their thermal conductivity. Different conductive materials classified as carbon, metallic, and ceramic-based fillers have been used for this task. However, the drawback with carbon and metalbased fillers is that they reduce the intrinsic insulating properties of polymer materials. Recently, boron nitride (BN), a ceramic-based filler was selected as the conductive filler of choice due to its combined excellent thermal conductivity and electrical insulation as well as high breakdown strength. Due to differences in polarities, boron nitride and polymer matrices form a weak interfacial bond. Therefore, the weak interfacial bond is commonly improved by surface chemical modification of the boron nitride fillers. Furthermore, most of the theoretical models are used to predict the thermal conductivities of boron nitride-polymers composites fitted well with experimental data. This proved that the models could be used to predict the properties of boron nitride composites before their experimental data. The review paper discusses the effect of boron nitride orientation, nanostructures, modification, and its synergy with other conductive fillers on the thermal conductivity and mechanical properties of the polymer matrices.
\end{abstract}

Keywords: polymer composites, hybrid conductive fillers, thermal conductivity, conductive fillers, boron nitride

\section{Introduction}

Due to an increase in heat accumulation for advanced electronic devices, there is an increasing demand for the fabrication of thermally conductive materials that can be used to dissipate the heat generated by these devices. Heat accumulation is a huge problem in advanced electronic devices as it reduces the lifetime and affects the reliability of the electronic devices [1]. For example, electronic devices with a high power density, such as LED lights and electronic speed controls, often undergo premature failure as a result of overheating [2]. In the past, polymer materials were used as thermal management materials due to their ease of processing, lightweight, low price, and electrical insulation [1-3]. However, the major drawback with polymers is their low thermal conductivities $[1,2,4]$ (Table 1 ). In order to compensate for the low thermal conductivity of the polymers, conductive fillers are incorporated into the polymer matrix [1-4]. Figure 1 below shows the number of publications on boron nitride composites from 2015 to date. An increase in the number of publications from 2015 to 2020 is observed from the bar graphs shown in Figure 1 below. This is because of the increasing severity of the heat accumulation problem in the electronic devices produced nowadays, 


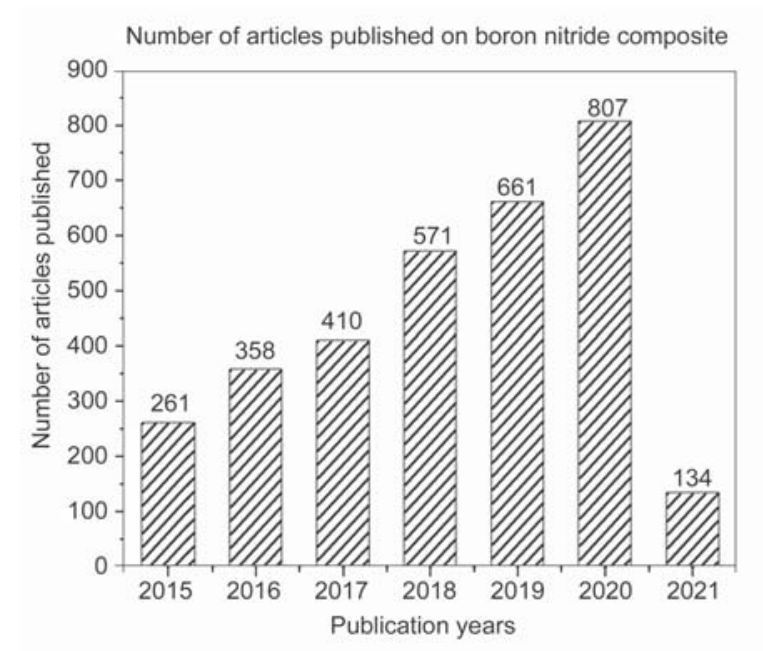

Figure 1. Recent publications on boron nitride composites from 2015 to date (This information was obtained from the web of science search query on this date 24-03-2021).

which forced researchers to investigate more on the thermal conductivity of polymer/boron nitride composites.

Conductive fillers can be classified as carbon, metallic, and ceramic-based fillers, as shown in Table 2.
Previously, carbon-based materials such as graphite, carbon fiber, carbon nanotubes, and graphene have been commonly used as thermally conductive fillers due to their high thermal conductivity [9]. However, the major drawback with the use of these conductive fillers is that the essential insulating property of the polymer matrix is reduced [9]. Recently, boron nitride (BN) has been selected as a thermally conductive filler of choice due to its combined excellent electrical insulation and thermal conductivity as well as high breakdown strength which are a result of its wide bandgap $(\sim 5.9 \mathrm{eV})[9,10]$.

However, it has been realized that a poor dispersion of the $\mathrm{BN}$ within the polymer matrix had a negative impact on the thermal conductivity values of the resultant composite. Therefore, the thermal conductivity of boron nitride can be improved by chemical surface modification of the boron nitride filler [4]. The surface modification of the filler improves the dispersion of fillers in the polymer matrix [3]. In a study by $\mathrm{Xu}$ and Chung [13], BN particles were effectively treated with acetone, acids (nitric and sulphuric acids), and silane. The thermal conductivity of the BN-epoxy

Table 1. Thermal conductivity values of selected polymers.

\begin{tabular}{|c|c|c|}
\hline Polymers & $\begin{array}{l}\text { Thermal conductivity } \\
{[\mathrm{W} /(\mathrm{m} \cdot \mathrm{K})]}\end{array}$ & References \\
\hline Low-density polyethylene (LDPE) & 0.30 & \multirow{6}{*}[5]{} \\
\hline High-density polyethylene (HDPE) & 0.44 & \\
\hline Polytetrafluoroethylene (PTFE) & 0.25 & \\
\hline Polyimide (PI) & 0.11 & \\
\hline Polyvinyl chloride (PVC) & 0.19 & \\
\hline Poly(ethylene terephthalate) (PET) & 0.15 & \\
\hline Polypropylene (PP) & 0.25 & [6] \\
\hline Cresol Novolac epoxy resin & $0.15-0.25$ & [7] \\
\hline Diglycidyl ether of Bisphenol-A (DGEBA) epoxy resin & 0.20 & [8] \\
\hline $\begin{array}{l}\text { Diglycidyl ether of terephthalylidene-bis-(4-amino-3-methylphenol } \\
\text { (DGETAM isotropic phase) epoxy resin }\end{array}$ & 0.35 & {$[8]$} \\
\hline $\begin{array}{l}\text { Diglycidyl ether of terephthalylidene -bis-(4-amino-3-methylphenol } \\
\text { (DGETAM liquid crystalline phase) epoxy resin }\end{array}$ & 0.38 & [8] \\
\hline
\end{tabular}

Table 2. Selected thermally conductive filler.

\begin{tabular}{|l|c|c|c|}
\hline \multicolumn{1}{|c|}{ Fillers } & Group types & $\begin{array}{c}\text { Thermal conductivity } \\
[\mathbf{W} / \mathbf{( m \cdot K} \cdot \mathbf{K})]\end{array}$ & References \\
\hline Graphene & Carbon-based & $4000-5000$ & 2966 \\
Diamond & & $>3000$ & \\
Carbon nanotubes (CNTs) & & 483 & \\
\hline Copper (Cu) & Metallic & 247 & \\
Aluminium (Al) & & 450 & \\
Sliver (Ag) & \multirow{2}{*}{ Ceramic } & 320 & \\
\hline Aluminium nitride (AIN) & & 320 & \\
Boron nitride (BN) & & 270 & \\
Silicon carbide (SiC) & & \\
\hline
\end{tabular}


composites reached a maximum value of $10.3 \mathrm{~W} /(\mathrm{m} \cdot \mathrm{K})$ at $57 \mathrm{vol} \% \mathrm{BN}$ content with silane treatment of the BN fillers, which was higher than that of BN-epoxy composites $(5.27 \mathrm{~W} /(\mathrm{m} \cdot \mathrm{K}))$ consisting of untreated BN fillers at the same filler content. This proved that filler surface treatment is an effective way of improving thermal conductivity. Without surface treatment, weak bonds would be formed at the interface between the polymer matrix and inorganic $\mathrm{BN}$ particles [1, 2]. In a polymer composite, a weak interfacial bonding limits the movement of energy from the matrix to the filler where it propagates the fastest $[1,13]$. When $\mathrm{BN}$ fillers are silane treated, the interaction at the filler-polymer matrix interface is improved because silane makes it easier for the inorganic filler, $(\mathrm{BN})$ to bond with the polymer matrix (epoxy resin) [2]. According to Zhang et al. [14], besides surface treatment, compatibilizers (such as maleic anhydride grafted polyethylene) can improve the interfacial interaction between a polyethylene matrix and hexagonal boron nitride and hence improve the thermal and mechanical properties of the composites. Furthermore, filler geometry can also affect the thermal conductivity of polymer composites [2]. For example, a higher in-plane thermal conductivity has been obtained with platelet-shaped fillers as compared to equiaxial-shaped fillers. However, the platelet-shaped fillers produce conductive materials that are anisotropic. This is because, during processing, the platelets are preferentially oriented in the flow direction [2]. This review paper discusses the effect of BN content, orientation, surface modification, compatibilization, and its synergistic effect with other fillers on the thermal conductivity and mechanical properties of polymer matrices. The paper further discusses different models for predicting the thermal conductivity of the BN/polymer composites.

\section{History, structure, and properties of boron nitride}

Boron nitride (BN) is a crystalline compound that is synthetically produced and is made up of equal amounts of nitrogen $(\mathrm{N})$ atoms and boron $(\mathrm{B})$ arranged in a honeycomb configuration $[1,10,15,16]$. BN was first synthesized in the 1840s by a British chemist by the name of Balman [10]. In the synthesis procedure, Balman used molten acid and potassium cyanide as precursors for the synthesis of BN [10]. This opened up an enormous amount of investigations on the synthesis of different types of BN nanostructures [10].
Up to date, the most commonly used methods for the synthesis of $\mathrm{BN}$ are the high-temperature pressure method [17], chemical exfoliation method [18], freeze-drying method [19], chemical vapor deposition method [20], boron ink method [21], microfludization [22], and liquid-phase exfoliation method [23]. Figure 2 shows hexagonal boron nitride of various thicknesses synthesized via the chemical deposition method. The chemical deposition method shows that the thickness of h-BN is controllable by controlling the growth of its atomic layers.

Furthermore, BN has a structure similar to that of graphite in which the carbon atoms are replaced by alternating $\mathrm{B}$ and $\mathrm{N}$ atoms [15]. BN is found in three crystalline forms, namely: cubic BN (c-BN, similar to diamond), hexagonal BN (h-BN, a layered structure like graphite), and wurtzite BN (w-BN, analogous to Ionsdaleite) [10]. Amongst the three forms of $\mathrm{BN}$, $\mathrm{h}$-BN, an $\mathrm{sp}^{2}$-hybridized 2D-layered insulator, is a highly crystalline form of BN under standard conditions. In the BN crystal structure, the bonding between the alternating $\mathrm{B}$ and $\mathrm{N}$ atoms is governed by robust B-N covalent bonds, and the stacking between the 2D layers is governed by weak van der Waals forces [16, $25,26]$. When compared with the $\mathrm{C}-\mathrm{C}$ covalent bonding nature of its counterpart, the $\mathrm{B}-\mathrm{N}$ bonding nature of $\mathrm{BN}$ is partially ionic due to the fact that the $\mathrm{N}$ atom has a higher electronegativity compared to the $\mathrm{B}$ atom [10]. Consequently, the optical, electrical, and substance properties of BN are not the same as those of graphite [10]. However, like most carbon materials, $\mathrm{BN}$ can also exist in several different nanostructures such as boron nitride nanotubes (BNNT), boron nitride nanosheets (BNNS), and boron nitride nanoribbons (BNNR), [10]. Other boron nanostructures include boron nitride fullerenes, boron nitride nanofibers (BNNF), and boron nitride nanopowders (BNNP), [10]. The synthesis procedures of these BN nanostructures have been extensively reviewed by Joy et al. [10]. As a filler material, BN has attracted enormous attention in both the scientific and engineering fields due to its fascinating properties such as excellent thermal conductivity, large energy band gap, thermal stability, chemical inertness, good resistance to oxidation, and significant mechanical properties [2628]. Most of these properties were found to be governed by its atomic structure [10]. In addition, $\mathrm{BN}$ is a perfect insulator and therefore suitable for heat dissipation in electronic devices that require both electrical insulation and increased thermal conductivity. 


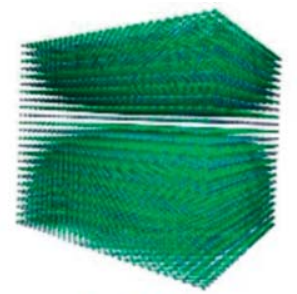

Bulk-h-BN

a)

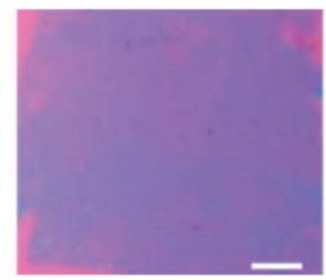

e)

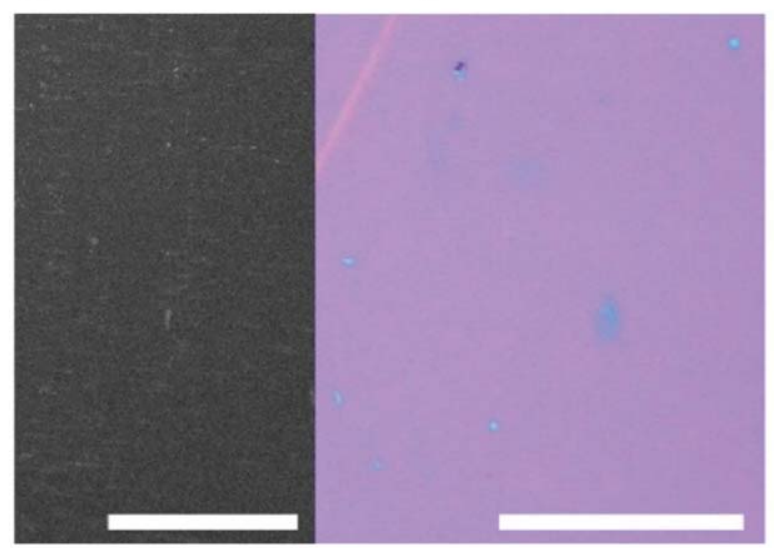

i)

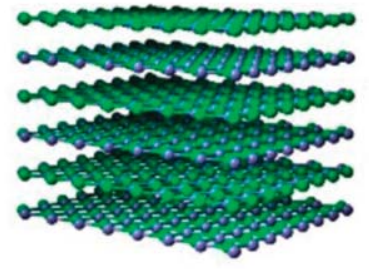

b)

Several-layered h-BN

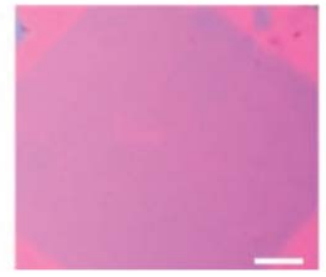

f)

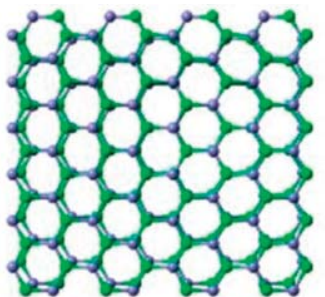

Few-layered h-BN

c)

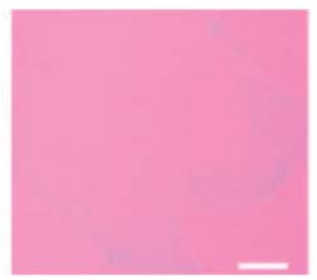

g)

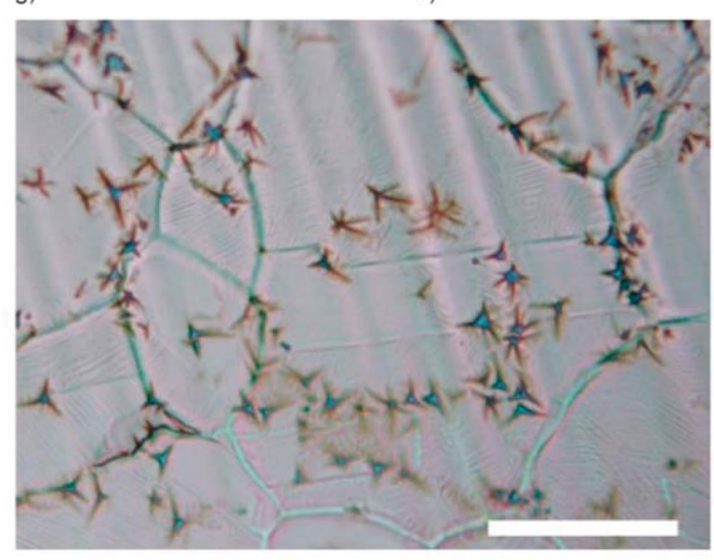

j)

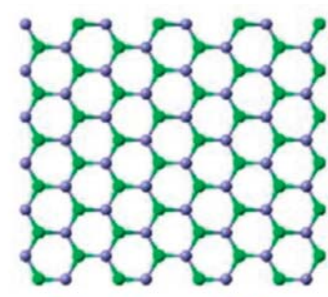

Single-layered h-BN

d)

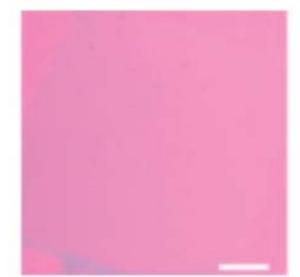

h)

Figure 2. Optical images of (a) bulk, (b) six-layer, (c) double-layer and (d) single-layer h-BN and (e-h) corresponding optical images of the different layered h-BNs grown on $\mathrm{SiO}_{2}$ substrates (scale bar of images (e-h) is $2 \mathrm{~mm}$ ); (i) SEM image of a few layered h-BN on Ni foil (left-hand-side image scale bar is $1 \mathrm{~mm}$ ) and optical image of a few layered h-BN film on $\mathrm{SiO}_{2}$ (right-hand-side image scale bar is $100 \mu \mathrm{m}$ ); (j) bulk highly crystalline h-BN star-like structures on Ni foil (scale bar is $100 \mu \mathrm{m}$ ) [24] (MDPI open access).

\section{Fabrication and resultant dispersion of boron nitride-based Polymer composites}

The morphology of polymer composites is influenced by several factors, which include filler content, preparation methods, filler modification, compatibilizers, particle size, filler shape, and type of polymer matrix $[2,6,14,29-31]$. The effect of filler content on the morphology of BN/polyethylene composites was reported by Ayoob et al. [31]. In this study, hexagonal boron nitride was added into the polyethylene matrices (i.e. LDPE and HDPE) at various filler contents, i.e., $2,5,10,20$, and $30 \mathrm{wt} \%$. In this study, the type of boron nitride used was hexagonal boron nitride (hBN). Scanning electron microscopy (SEM) images showed a uniform distribution of the h-BN in the polyethylene matrix. However, a lot of agglomeration was observed in nanocomposites consisting of more than $10 \mathrm{wt} \% \mathrm{~h}-\mathrm{BN}$. Furthermore, the incorporation of
h-BN into the polyethylene matrix led to a disordered morphology when compared with pure polyethylene. This effect became more pronounced with increasing h-BN content. Similarly, Yu et al. [30] reported on the effect of filler (h-BN) content for a system that included BN and cellulosic fiber. Micronsized voids were observed between the cellulosic fiber matrix and BN filler particles. At a lower filler loading, the BN particles were more evenly distributed on the cellulosic fiber matrix surface. The BN particles kept a certain distance from each other and rarely made contact. However, at higher BN filler loading, the micron-sized voids were gradually occupied by BN particles. In this case, the BN particles made contact with each other along the cellulosic fiber matrix skeleton. The increased contact area between the h-BN filler particles led to the formation of networks called heat conductive pathways in the 
composite. These pathways were just the needed structures to reduce thermal resistance in the composite. It has been shown that the synergy of BN with other fillers and preparation methods used in the fabrication of polymer composites can also influence their morphology. For example, Wie and Kim [32] prepared raw BN (R-BN)/Epoxy, graphene oxide (GO)/R-BN/epoxy, and GO/polysilazane coated BN (P-BN)/epoxy composite films via solution mixing followed by solvent casting and then curing. The morphologies of the prepared composite films were studied using cross-sectional SEM microscopy. The SEM image of the raw BN (R-BN)/epoxy composite showed a distinctly layered morphology due to the downward diffusion of the high-density R-BN during the curing process (see Figure $3 \mathrm{a}$ ). This occurrence hinders filler dispersion in the matrix and negatively affects composite performance. Figure $3 \mathrm{~d}$ shows the presence of numerous gaps around the fillers in the R-BN/epoxy composites. This was an indication of the poor wettability of the R-BN fillers. These gaps may hinder the flow of heat, which may result in heat loss. However, as shown by Figure 3b, the introduction of GO into the composite during the preparation process improved the degree of $\mathrm{BN}$ filler dispersion in the epoxy matrix. This is because the well-dispersed GO prevented the downward diffusion of the $\mathrm{BN}$ fillers during the curing process and therefore improved the degree of $\mathrm{BN}$ dispersion in the matrix. However, Figure 3e shows that the incorporation of GO did not improve interfacial adhesion in the epoxy composite. This problem was rectified via the surface modification of $\mathrm{BN}$, which provided structural similarity with the epoxy matrix, as shown by Figure $3 \mathrm{c}$ and Figure $3 \mathrm{f}$.

In another study, Yang et al. [33] prepared polyethylene hexagonal boron nitride (PE/h-BN) composite sheets with improved thermal conductivity by annealing a multi-layered structure of alternating highdensity PE (HDPE)/h-BN composites and low-density PE (LDPE) layers. In order to study the dispersion of fillers during annealing, SEM was used. Through SEM, the cross-sections of the multi-layered sheets annealed at $200^{\circ} \mathrm{C}$ for different times were studied. The SEM images of these multilayers sheets were also compared to the SEM images of multi-layered sheets consisting of h-BN particles randomly distributed in both HDPE and LDPE matrices. From the SEM images of the multi-layered sheets, it was observed that the shrinkage of the composite layers continuously occurred for $2 \mathrm{~h}$ (120 min) annealing time. In the unannealed multi-layered sheets, the h-BN platelets dispersed in the HDPE matrix were dispersed parallel to the interfaces between neighboring LDPE layers. After annealing for different time lengths, the thickness of the h-BN/HDPE composite layers shrank, and the concentration of $h-$ $\mathrm{BN}$ was increased with annealing time. After annealing for $30 \mathrm{~min}$, the composite layers of the multi-layered sheet became significantly thinner than before. As a result, the concentration of h-BN was significantly increased, and the fillers began to percolate. Increasing the annealing time led to a further decrease in the composite layer thickness, and the contact area

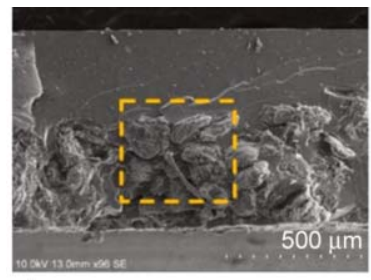

a)

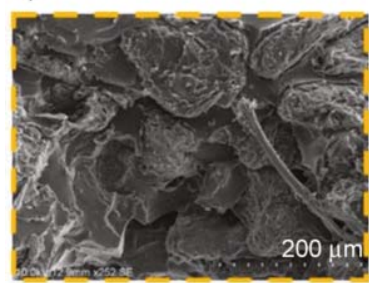

d)

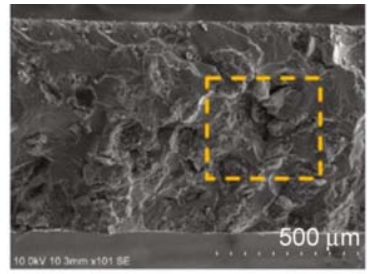

b)

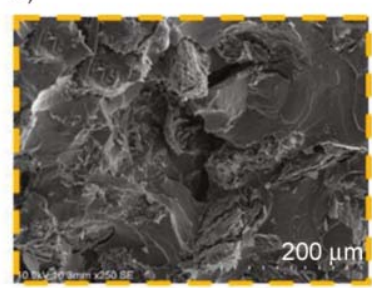

e)

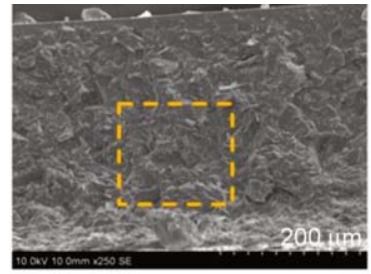

c)

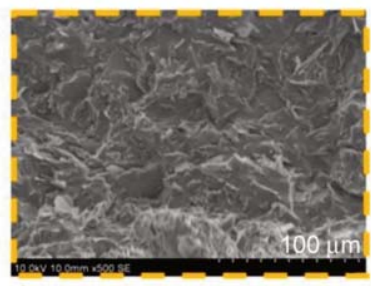

f)

Figure 3. SEM images of the cross-sectional area of the prepared BN/epoxy composites: (a) raw BN (R-BN)/epoxy composite (scale bar is $500 \mu \mathrm{m}$ ), (b) graphene oxide (GO)/R-BN/epoxy composite (scale bar is $500 \mu \mathrm{m}$ ), (c) GO/polysilazane coated BN (P-BN)/epoxy composite (scale bar is $200 \mu \mathrm{m}),(\mathrm{d}, \mathrm{e}, \mathrm{f})$ are the corresponding magnified areas of the marked areas (in a yellow square) in (a, b, c) ((scale bar of (d) and (e) is $200 \mu \mathrm{m}$ and scale bar of (f) is $100 \mu \mathrm{m})$ [32] (MDPI open access). 
Table 3. Selective studies on preparation and morphology of boron nitride-polymer composites.

\begin{tabular}{|c|c|c|c|c|}
\hline Polymer composites & Filler content & Mixing method & Results discussed on morphology & References \\
\hline $\begin{array}{l}\text { BN/ABS, } \\
\text { BN/ABS/HDPE, } \\
\text { BN/ABS/PE- } \text {-MA com- } \\
\text { posites, } \\
\text { ABS = Acrylonitrile buta- } \\
\text { diene styrene, } \\
\text { HDPE = high density } \\
\text { polyethylene, } \\
\text { PE-g-MA = maleic anhy- } \\
\text { dride grafted polyethyl- } \\
\text { ene }\end{array}$ & $\begin{array}{l}40 \mathrm{wt} \% \text { of } \mathrm{BN} \\
\text { particles }\end{array}$ & Injection molding & $\begin{array}{l}\text { - Scanning electron microscopy (SEM) images of } \\
\text { fractured surfaces showed an even distribution } \\
\text { of } 40 \mathrm{wt} \% \mathrm{BN} \text { platelets in all samples consisting } \\
\text { of ABS, ABS/HDPE, ABS/PE-g-MA matrices. } \\
\text { - Voids were observed in BN/ABS and BN/ABS/ } \\
\text { HDPE composites. Cracks were also observed } \\
\text { around the edges of BN particles, indicating } \\
\text { weak interfaces. } \\
\text { - No voids were observed in BN/ABS/PE- } g \text {-MA } \\
\text { composites indicating that maleic anhydride im- } \\
\text { proved the adhesion between the matrix and BN } \\
\text { particles. }\end{array}$ & {$[2]$} \\
\hline $\begin{array}{l}\mathrm{PP} / \text { micro-BN, } \\
\mathrm{PP} / \text { nano-BN composites, } \\
\mathrm{PP}=\text { polypropylene, } \\
\text { micro-BN = microsized } \\
\text { boron nitride, } \\
\text { nano-BN = nanosized } \\
\text { boron nitride }\end{array}$ & $\begin{array}{l}3,6 \text { and } 9 \mathrm{wt} \% \\
\text { of BN particles }\end{array}$ & $\begin{array}{l}\text { Melt mixing of PP and BN } \\
\text { fillers using a two-roll open } \\
\text { mill and hot pressing. }\end{array}$ & $\begin{array}{l}\text { - Pure PP fractured surfaces were smooth and } \\
\text { those of PP/micro-BN composites were rougher } \\
\text { with increasing filler content, indicating a } \\
\text { stronger interfacial interaction between micro- } \\
\text { BN and PP. } \\
\text { - Nano-BN particles were uniformly distributed in } \\
\text { the PP matrix at various filler contents, indicating } \\
\text { a good interfacial interaction. } \\
\text { - The nano-BN particles were extremely dispersed } \\
\text { in PP as compared with micro-BN particles. All } \\
\text { the nano-BN particles were isolated from each } \\
\text { other and therefore did not make contact at } \\
9 \text { wt } \% \text { filler loading. However, flaky micro-BN } \\
\text { particles created many short lines in the PP/ } \\
\text { micro-BN composites, which gradually connect- } \\
\text { ed with increasing filler loading. This caused the } \\
\text { formation of thermal paths, which improved } \\
\text { thermal conductivity. }\end{array}$ & [29] \\
\hline $\begin{array}{l}\mathrm{PE} / \mathrm{BN}, \\
\mathrm{PE} / \mathrm{K}-\mathrm{BN}, \\
\mathrm{PE} / \mathrm{M}-\mathrm{BN} \text { composites, } \\
\mathrm{PE}=\text { polyethylene, } \\
\mathrm{K}-\mathrm{BN}=\mathrm{KH} 550 \text { treated } \\
\text { boron nitride, } \\
\mathrm{PE} / \mathrm{M}-\mathrm{BN}=(\mathrm{PE}+ \\
\mathrm{PE}-\mathrm{g}-\mathrm{MAH}) / \mathrm{BN}, \\
\mathrm{PE}-\mathrm{g} \text {-MAH = maleic } \\
\text { anhydride grafted poly- } \\
\text { ethylene, } \\
\text { KH550 = } \gamma \text {-aminopropyl- } \\
\text { triethoxysilane }\end{array}$ & $\begin{array}{l}10 \mathrm{wt} \% \mathrm{BN} \text { par- } \\
\text { ticles }\end{array}$ & $\begin{array}{l}\text { Compounding of } \mathrm{PE} \text { and } \\
\mathrm{BN} \text { particles in an internal } \\
\text { mixer at } 180^{\circ} \mathrm{C} \text { for } 8 \mathrm{~min} \text {, } \\
\text { and rotation speed of } \\
30 \mathrm{rpm} \text {. }\end{array}$ & $\begin{array}{l}\text { - SEM images of fractured composite surfaces } \\
\text { showed some BN aggregates in composites con- } \\
\text { sisting of } 10 \mathrm{wt} \% \mathrm{BN} \text {. However, reasonably uni- } \\
\text { form dispersion and good distribution were ob- } \\
\text { served for composites consisting of } 10 \mathrm{wt} \% \\
\text { M-BN and } 10 \mathrm{wt} \% \mathrm{~K}-\mathrm{BN} \text {, which was an indica- } \\
\text { tion that surface functionalization of BN particles } \\
\text { and addition of PE- } \mathrm{g} \text {-MAH can improve the dis- } \\
\text { tribution of BN particles with less aggregation. }\end{array}$ & {$[14]$} \\
\hline $\begin{array}{l}\mathrm{iPP} / \mathrm{h}-\mathrm{BN} / \mathrm{MWCNTs} \text { and } \\
\mathrm{iPP} / \mathrm{h}-\mathrm{BN} / \mathrm{GNPs} \text { compos- } \\
\text { ites, } \\
\mathrm{iPP}=\text { isotactic polypropy- } \\
\text { lene, } \\
\text { MWCNTs = multi-wall } \\
\text { carbon nanotubes, } \\
\text { GNPs = graphene } \\
\text { nanoplatelets }\end{array}$ & $\begin{array}{l}10,20 \text { and } \\
30 \mathrm{wt} \% \text { of } \mathrm{BN}\end{array}$ & Melt-mixing & $\begin{array}{l}\text { - Even though thermally conductive networks } \\
\text { were formed in iPP/h-BN composites at high h- } \\
\text { BN particle contents, there were still lots of iso- } \\
\text { lated h-BN particles in the composites. There- } \\
\text { fore, incorporated MWCNTs or GNPs acted as } \\
\text { 'bridges' to connect these isolated h-BN particles } \\
\text { and then further improved the thermal conduc- } \\
\text { tivity of the iPP/h-BN composites. }\end{array}$ & [34] \\
\hline $\begin{array}{l}\mathrm{BN} / \mathrm{EP} \text { composites, } \\
\mathrm{EP}=\text { epoxy }\end{array}$ & $\begin{array}{l}5 \text { and } 20 \mathrm{vol} \% \\
\text { of h-BN or } \\
\text { c-BN particles }\end{array}$ & $\begin{array}{l}\text { Incorporation of various } \\
\text { contents of surface-modi- } \\
\text { fied hexagonal boron ni- } \\
\text { tride (h-BN) and cubic } \\
\text { boron nitride (c-BN) pow- } \\
\text { ders to epoxy resin matri- } \\
\text { ces }\end{array}$ & $\begin{array}{l}\text { - The cross-sectional morphology of the compos- } \\
\text { ite materials became increasingly rougher as } \\
\text { their BN content was increased. }\end{array}$ & {$[35]$} \\
\hline
\end{tabular}


between fillers was increased, which favored the formation of percolated thermal conduction pathways. In addition to that, an increase in annealing time also increased the orientation of h-BN in the HDPE matrix. At higher annealing times, the fillers in the composite layers were highly oriented, and the h-BN platelets were arranged parallel to the interfaces between neighboring LDPE layers. However, the multilayered control sheet in which the h-BNs were randomly distributed in both HDPE and LDPE matrices only showed a typical sea-and-island-like structure with no preferred orientation. Table 3 is a summary of different methods used in the fabrication of boron nitride-polymer composites, as well as the obtained morphological properties.

\section{Selective polymer matrices for fabrication of polymer/boron nitride (BN) composites}

Nowadays, a lot of effort has been focused on improving the thermal conductivity of the polymers using conductive fillers [10]. The aim of this section is to classify the different polymer matrices used in polymer/BN composites as well as the effectiveness of BN in different polymer matrices (Table 4). According to this section, the polymer matrices can be broadly classified into two groups (i.e., thermoplastics and thermosets). Based on Table 4 below, thermoplastics are the most utilized polymer group in the preparation of boron nitride-polymer composites. Jing et al. [36], used poly(vinyl alcohol) (PVA) as a polymer matrix to prepare biocompatible hydroxylated boron nitride/PVA interpenetrating hydrogels with enhanced mechanical and thermal properties for biomedical applications. This is because PVA-based hydrogels are considered good cartilage replacement materials due to their tissue-like viscoelasticity, excellent biocompatibility, and high hydrophilicity. In another study, Fei et al. [37] used thermoplastic polyurethane (TPU) to prepare flexible polyurethane/boron nitride composites with improved thermal conductivity. When compared with other polymer matrices, TPU was used because of its superior properties, such as excellent flexibility, elasticity, chemical resistance, abrasive resistance, good adhesion, and good physical properties. Du and Cui [29] used polypropylene (PP) as a polymer matrix in the preparation of micro, and nano-sized boron nitride-filled polypropylene composites with enhanced heat dissipation ability. Polypropylene was used as a polymer matrix because it was considered a recyclable insulating material with excellent electrical insulating properties. Table 4 below is a summary of some of the polymer matrices used in the fabrication of boron nitridepolymer composites, as well as the corresponding composite properties.

\section{The effect of surface modification on the thermal conductivity of BN-polymer composites}

Thermally conductive networks in BN-polymer composites depend on the contact area of fillers and how well the fillers (in this case $\mathrm{BN}$ ) are dispersed in the polymer composites. These contact points between the filler $(\mathrm{BN})$ particles are found to be favorable to increase the thermal conductivity of the composites. Higher filler contents transfer energy more efficient when the contact area between the fillers is larger. However, higher filler contents lead to the formation of voids and aggregates formed in the polymer composites $[48,49]$. It is well-known that the conductive pathways are hindered by voids formed between the filler particles and polymer matrix, which results in difficulties for the conduction of heat. Therefore, the surface modification of inorganic BN particles has been found to be an effective method to enhance thermal conductivity and the interaction between the filler-polymer matrix [50, 51].

Many researchers have reported on the use of various surface treatment methods such as silane coupling agents, surfactants, titanate coupling agents, and inorganic coatings for enhancing the dispersion of the filler filler-polymer matrix contact and thus reducing the thermal resistance $[7,48,52-55]$. Silane coupling agents are found to be effective modifiers and are popular amongst surface treatment methods. They contain different functional groups, which allow their molecules to bond with inorganic materials, thus making them useful for enhancing the interaction between the filler and polymer matrix [55]. Wie et al. [52] modified the surface of the boron nitride using polysilazane (PSZ) and (3-glycidyloxypropyl) tri-methoxysilane (GPTMS) to enhance thermal conductivity. There was an improvement of the thermal conductivity to $7.014 \mathrm{~W} /(\mathrm{m} \cdot \mathrm{K})$ of the composites containing filler loading of $50 \mathrm{vol} \% \mathrm{PSZ}$ and GPTMS-coated BN materials. This value was approximately 50 times higher as compared to that one of neat epoxy. One can suggest that there was a tremendous improvement of thermal conductivity, 
Table 4. Summary of some of the polymer matrices used during the fabrication BN based polymer composites/nanocomposites.

\begin{tabular}{|c|c|c|c|c|}
\hline Nanocomposites & $\begin{array}{l}\text { Type of polymer } \\
\text { (thermoset or } \\
\text { thermoplastic) }\end{array}$ & $\begin{array}{l}\text { Typical example of } \\
\text { nanocomposites }\end{array}$ & $\begin{array}{c}\text { Nanocomposite properties (thermal } \\
\text { conductivity, mechanical, thermal stability } \\
\text { properties, etc.) }\end{array}$ & References \\
\hline $\begin{array}{l}\text { Poly(vinyl alcohol) } \\
\text { (PVA)/BN }\end{array}$ & Thermoplastic & $\begin{array}{l}\text { PVA/OH-BNNS hydrogels } \\
\text { OH-BNNS = hydroxylated } \\
\text { boron nitride nanosheets }\end{array}$ & $\begin{array}{l}\text { The incorporation of } 0.12 \mathrm{wt} \% \mathrm{OH}-\mathrm{BNNS} \text { in a } \\
\text { PVA matrix increased the thermal conductivity } \\
\text { and diffusivity of the PVA/OH-BNNS hydro- } \\
\text { gels by } 5 \text { and } 15 \% \text {, respectively. }\end{array}$ & {$[36]$} \\
\hline Polyurethane/BN & Thermoplastic & $\begin{array}{l}\text { TPU/BN } \\
\text { TPU = thermoplastic } \\
\text { polyurethane }\end{array}$ & $\begin{array}{l}\text { Composite exhibited } 1390 \% \text { enhancement in } \\
\text { thermal conductivity with the incorporation of } \\
50 \mathrm{wt} \% \mathrm{BN} \text {. }\end{array}$ & {$[37]$} \\
\hline Cellulose/BN & Natural polymer & $\begin{array}{l}\text { OH-BNNS/CNF multilayer } \\
\text { films } \\
\mathrm{CNF}=\text { cellulose nanofiber }\end{array}$ & $\begin{array}{l}\text { There was a significant increase of in-plane } \\
\text { thermal conductivity in the multilayer films, } \\
\text { and the unit weight filler exhibited an increased } \\
\text { thermal conductivity efficiency up to } 1142 \% \text {. }\end{array}$ & {$[38]$} \\
\hline Polystyrene (PS)/BN & Thermoplastic & BNNS/PS nanocomposite & $\begin{array}{l}\text { The } 5: 1 \text { styrene:BN feeding ratio improved } \\
\text { thermal conductivity values up to a maximum } \\
\text { of } 1375 \% \text {. }\end{array}$ & {$[39]$} \\
\hline Polypropylene (PP)/BN & $\begin{array}{l}\text { Thermoplastic, } \\
\text { polyolefin }\end{array}$ & $\begin{array}{l}\text { Micro- and nano-sized } \\
\text { BN/polypropylene com- } \\
\text { posites }\end{array}$ & $\begin{array}{l}\text { The thermal conductivity was higher for micro- } \\
\text { sized BN/PP composites as compared to that of } \\
\text { PP/nano-BN composites at the same BN filler } \\
\text { loading. }\end{array}$ & {$[29]$} \\
\hline $\begin{array}{l}\text { Polyacrylamide } \\
(\mathrm{PAM}) / \mathrm{BN}\end{array}$ & Thermoplastic & $\begin{array}{l}\text { h-BN/PAM nanocomposite } \\
\text { hydrogels }\end{array}$ & $\begin{array}{l}\text { The incorporation of h-BN nanosheets im- } \\
\text { proved the elongation at break of the } \mathrm{h}-\mathrm{BN} / \mathrm{BN} \\
\text { nanocomposite hydrogels up to } 1000 \% \text {. This } \\
\text { signified that the interfacial interaction between } \\
\text { the h-BN nanosheets and PAM matrix was } \\
\text { strong. This strong interfacial bond can there- } \\
\text { fore improve the thermal conductivity of the } \\
\text { composites hydrogels. }\end{array}$ & [40] \\
\hline $\begin{array}{l}\text { Polycaprolactone } \\
(\mathrm{PCL}) / \mathrm{BN}\end{array}$ & $\begin{array}{l}\text { Thermoplastic, } \\
\text { polyester }\end{array}$ & $\begin{array}{l}\text { PCL/PLA blends incorpo- } \\
\text { rated with h-BN } \\
\text { nanoplatelets, } \\
\text { PLA = polylactic acid }\end{array}$ & $\begin{array}{l}\text { Adding the h-BN nanoplatelets increased the } \\
\text { thermal conductivity of PCL/PLA blends by } \\
400 \% \text {. }\end{array}$ & [41] \\
\hline Polyacrylonitrile/BN & Thermoplastic & $\begin{array}{l}\text { Polyacrylonitrile/h-BN } \\
\text { composites }\end{array}$ & $\begin{array}{l}\text { At } 10 \mathrm{wt} \% \text { h-BN the composites had improved } \\
\text { thermal stability }\left(280^{\circ} \mathrm{C}\right) \text {, higher ionic conduc- } \\
\text { tivity }\left(1.0 \cdot 10^{-3} \mathrm{~S} / \mathrm{cm}\right) \text {, larger electrolyte uptake } \\
(1200 \%) \text {, and best electrochemical stability } \\
(4.7 \mathrm{~V}) \text {. }\end{array}$ & [42] \\
\hline $\begin{array}{l}\text { Acrylonitrile butadi- } \\
\text { ene styrene (ABS) } \\
\text { copolymer/BN }\end{array}$ & Thermoplastic & $\begin{array}{l}\mathrm{ABS} / \mathrm{h}-\mathrm{BN}, \mathrm{ABS} / \mathrm{mBN} \\
\mathrm{mBN}=\text { modified } \mathrm{BN}\end{array}$ & $\begin{array}{l}\text { The thermal conductivity of the } \mathrm{ABS} / \mathrm{mBN} \\
\text { composite was improved } 2.6 \text { times more than } \\
\text { pure } \mathrm{ABS} \text { at } 20 \mathrm{wt} \% \mathrm{mBN} \text {. }\end{array}$ & [43] \\
\hline Epoxy/BN & Thermoset & $\begin{array}{l}\text { PCB-BN/epoxy, } \\
\text { PCB-BN = polyphosp- } \\
\text { hazene-coated BN }\end{array}$ & $\begin{array}{l}\text { PCB-BN improves the thermal transport per- } \\
\text { formance of epoxy resins. Thermal conductivity } \\
\text { of } 0.708 \mathrm{~W} /(\mathrm{m} \cdot \mathrm{K}) \text { at } 20 \mathrm{wt} \% \text { PCB-BN particle } \\
\text { loading was observed. This was } 3.7 \text { times high- } \\
\text { er as compared to that of pristine epoxy. }\end{array}$ & {$[44]$} \\
\hline \multirow[t]{2}{*}{ Polyimide (PI)/BN } & Thermoset & $\begin{array}{l}\mathrm{PI} / \text { micro-BN and } \\
\mathrm{PI} / \text { nano-BN }\end{array}$ & $\begin{array}{l}\text { Composites consisting of } 30 \mathrm{wt} \% \text { micro-BN } \\
\text { and nano-BN at a } 7: 3 \mathrm{PI}: \mathrm{BN} \text { ratio showed the } \\
\text { highest thermal conductivity. }\end{array}$ & {$[45]$} \\
\hline & & $\begin{array}{l}\text { BN-c-MWCNT/PI films, } \\
\text { BN-c-MWCNT = Boron } \\
\text { nitride coated multiwalled } \\
\text { carbon nanotubes }\end{array}$ & $\begin{array}{l}\text { The thermal conductivity of films consisting of } \\
30 \mathrm{wt} \% \text { BN-c-MWCNTs was enhanced by } \\
106 \% \text {. }\end{array}$ & {$[46]$} \\
\hline Cyanate ester/BN & Thermoset & $\begin{array}{l}\text { Cyanate ester/silane cou- } \\
\text { pling agent modified BN }\end{array}$ & $\begin{array}{l}\text { The incorporation of } 23.6 \mathrm{wt} \% \mathrm{BN} \text { increased } \\
\text { the thermal conductivity of the composite to } \\
1.33 \mathrm{~W} /(\mathrm{m} \cdot \mathrm{K}) \text {, which was } 4.6 \text { times more than } \\
\text { that of the present matrix. }\end{array}$ & {$[47]$} \\
\hline
\end{tabular}


which was attributed to the treated surface of boron nitride using two-step surface modification. This indicated that their methods were more effective for enhancing thermal conductivity in comparison to other reported studies on BN-polymer composites. Chung and Lin [7] studied the thermal conductivity of epoxy composites filled with synthesized h-BN particles. The h-BN surface was treated with 3-glycidoxypropyltrimethoxysilane (GPTMS). It was reported that the GPTMS reduced the voids and thermal barrier between the filler and matrix, which resulted in a slight increase in thermal conductivity from 15.1 to $20.3 \%$ as a result of GPTMS surface treatment.

Furthermore, Lee and Kim [56], used a one-step exfoliation and functionalization method to prepare an amine-group functionalized hybrid filler consisting of boron nitride and aluminum nitride $\left(\mathrm{BA}-\mathrm{NH}_{2}\right)$. The hybrid filler $\left(\mathrm{BA}-\mathrm{NH}_{2}\right)$ and a cellulose nanofiber (CNF) were used to prepare a thermally conductive film $\left(\mathrm{CNF} / \mathrm{BA}-\mathrm{NH}_{2}\right)$ via vacuum filtration and hotpress processing. After surface treatment of each filler in the hybrid filler, the dispersion of the hybrid filler in the film matrix was improved. This was due to hydrogen bonding interactions which improved the interfacial adhesion between the filler and matrix. Furthermore, treated aluminum nitride particles deposited on surface-treated BN particles promoted the formation of heat transfer paths along the throughplane direction. The thermal conductivity was increased from $0.5 \mathrm{~W} /(\mathrm{m} \cdot \mathrm{K})$ (neat $\mathrm{CNF}$ film) to $5.93 \mathrm{~W} /(\mathrm{m} \cdot \mathrm{K})$ (at $50 \mathrm{wt} \% \mathrm{BN}$ filler content), which was a $1092 \%$ increase compared with the neat CNF film. Table 5 illustrates a summary of the selective studies on the thermal conductivity of BN-polymer composites.

\section{Thermal conductivity of the boron nitride-hybrid composites}

Recently, several researchers have shown a tremendous interest in the incorporation of thermally conductive mixed fillers (hybrid fillers) into polymer matrices as a means of improving the low thermal conductivity of polymers [62-66]. The hybrid conductive fillers are easily dispersed in the polymer matrix, and therefore they reduce the amount of voids in the matrix [67]. Methods such as simple mixing with a paste mixer, direct blending, physical adsorption, chemical bonding, and hot-pressing are some of the methods used for the preparation of hybrid thermally conductive composites. Methods such as the direct blending method are suitable for use when thermally conductive fillers with different sizes are involved. This method mainly focuses on the spatial matching of thermally conductive fillers with different sizes [62, 67, 68]. Jiang et al. [69] prepared functionalized graphene (GR)-boron nitride (BN)-polystyrene (PS) composites by solution blending. It was reported that the thermal conductivity of the GR-BN-PS composites reached the maximum of $0.24 \mathrm{~W} /(\mathrm{m} \cdot \mathrm{K})$ which was slightly higher than that of GR-PS composites $(0.22 \mathrm{~W} /(\mathrm{m} \cdot \mathrm{K}))$ and the pure PS $(0.15 \mathrm{~W} /(\mathrm{m} \cdot \mathrm{K})$. In order to understand the effectiveness of conductive hybrid fillers, thermal enhancement $(\phi)$ parameters and synergistic efficiency $(f)$ are used to estimate the degree of thermal conductivity enhancement in the composites and they are expressed by Equation (1) and (2):

$\phi=\frac{\lambda_{\text {com }}-\lambda_{\mathrm{P}}}{\lambda_{\mathrm{P}}} \cdot 100 \%$

where $\lambda_{\text {com }}$ and $\lambda_{P}$ represents the thermal conductivity of polymer-based composites and pure polymer samples, respectively.

$f=\frac{\lambda_{\text {sefc }}-\lambda_{\mathrm{P}}}{\left(\lambda_{\mathrm{f} 1}-\lambda_{\mathrm{P}}\right)+\left(\lambda_{\mathrm{f} 2}-\lambda_{\mathrm{P}}\right)}$

where $\lambda_{\text {sefc }}$ represents the thermal conductivities of the synergistic effect of two fillers in the composites, $\lambda_{\mathrm{f} 1}$ and $\lambda_{\mathrm{f} 2}$ represents the thermal conductivities of the two fillers in the composites $[6,70]$. A high value of $f(>1)$ means that there is a high probability of obtaining higher thermal conductivity and vice versa [6]. Yang et al. [70] incorporated graphene nanoplatelets (GNPs) into poly (ethylene glycol) (PEG)/ boron nitride $(\mathrm{BN})$ composite phase change materials (PCMs). The results revealed that the thermal enhancement $(\phi)$ of the PEG/BN/GNP PCM composites was enhanced with the incorporation of $1 \mathrm{wt} \%$ GNP content. It was also observed that the synergistic efficiency $(f)$ increased with increasing BN content which was higher than 1 for all the PEG/BN/GNP composites PCMs. This indicated that there was an increase in the synergistic efficiency of BN and GNP with an increasing BN content. In another study, Wu et al. [71] investigated the synergistic effects of boron nitride Nanosheets (BNNSs) and silver ( $\mathrm{Ag}$ ) nanoparticles on the thermal conductivity and electrical properties of epoxy (EP) Nanocomposites. The epoxy nanocomposites consisting of a hybrid nanofiller were denoted as EP-AgBN, and those without a hybrid 
Table 5. Summary of selective studies on the thermal conductivity of BN-polymer composites.

\begin{tabular}{|c|c|c|c|c|}
\hline Composites system & Filler or fillers & $\begin{array}{l}\text { Technique used to enhance } \\
\text { thermal conductivity }\end{array}$ & $\begin{array}{l}\text { Discussions and thermal conductivity of } \\
\text { the composites } \\
{[\mathrm{W} /(\mathrm{m} \cdot \mathrm{K})]}\end{array}$ & References \\
\hline $\begin{array}{l}\text { Surface treated boron ni- } \\
\text { tride (BN)/epoxy-terminat- } \\
\text { ed dimethylsiloxane } \\
\text { (ETDS) composites }\end{array}$ & $\begin{array}{l}\mathrm{BN}, \\
\text { surface-treated } \\
\mathrm{BN}\end{array}$ & $\begin{array}{l}\text { The sol-gel method was used to } \\
\text { modify BN particles with silica } \\
\text { using tetraethyl orthosilicate } \\
\text { (TEOS). }\end{array}$ & $\begin{array}{l}\text { The thermal conductivities of surface-modi- } \\
\text { fied } \mathrm{BN} / \mathrm{ETDS} \text { composites ranged from } 0.2 \\
\text { to } 3.1 \mathrm{~W} /(\mathrm{m} \cdot \mathrm{K}) \text { which were above those of } \\
\text { unmodified BN/ETDS composites at the } \\
\text { same filler content. }\end{array}$ & [53] \\
\hline $\begin{array}{l}\text { h-BN-KH550/polytetraflu- } \\
\text { oroethylene (PTFE), } \\
\text { h-BN/PTFE composites }\end{array}$ & $\begin{array}{l}\text { h-BN, } \\
\text { h-BN-KH550 }\end{array}$ & $\begin{array}{l}\text { h-BN platelets were treated } \\
\text { with a silane coupling agent } \\
\text { (KH550) }\end{array}$ & $\begin{array}{l}\text { h-BN surface modification improved inter- } \\
\text { facial adhesion between h-BN platelets and } \\
\text { PTFE matrix and reduced the in-plane orien- } \\
\text { tation degree of h-BN platelets in the PTFE } \\
\text { matrix, which consequently enhanced the } \\
\text { thermal conductivity of the composites. The } \\
\text { thermal conductivity of h-BN-KH550/PTFE } \\
\text { composites reached } 0.722 \mathrm{~W} /(\mathrm{m} \cdot \mathrm{K}) \text { at } \\
30 \text { vol } \% \text { filler content, which was } 2.7 \text { times } \\
\text { that of pure PTFE. }\end{array}$ & [57] \\
\hline $\begin{array}{l}\text { Functionalised-BN } \\
\text { (f-BN)/polyimide compos- } \\
\text { ites }\end{array}$ & $\begin{array}{l}\mathrm{BN}, \\
\text { f-BN }\end{array}$ & $\begin{array}{l}\text { Functionalization of boron ni- } \\
\text { tride surfaces with } \gamma \text {-glyci- } \\
\text { doxypropyltrimethoxysilane } \\
(\mathrm{KH}-560) \text { and aminopropy- } \\
\text { lisobutyl polyhedral oligomeric } \\
\text { silsesquioxane }\left(\mathrm{NH}_{2} \text {-POSS). }\right.\end{array}$ & $\begin{array}{l}\text { f-BN/PI composites exhibited a thermal con- } \\
\text { ductivity coefficient of } 0.71 \mathrm{~W} /(\mathrm{m} \cdot \mathrm{K}) \text { at } \\
30 \mathrm{wt} \% \mathrm{f}-\mathrm{BN} \text {, which was higher than that of } \\
\mathrm{BN} / \mathrm{PI} \quad \text { composites at } 30 \mathrm{wt} \% \\
(0.69 \mathrm{~W} /(\mathrm{m} \cdot \mathrm{K})) \text {. }\end{array}$ & {$[58]$} \\
\hline $\begin{array}{l}\text { Boron nitride/cellulosic } \\
\text { fiber insulating composites }\end{array}$ & h-BN & $\begin{array}{l}\text { Grafting of (3-aminopropyl) tri- } \\
\text { ethoxysilane (APTES) onto the } \\
\text { surface of h-BN fillers and in- } \\
\text { corporation of dual-sized fillers. }\end{array}$ & $\begin{array}{l}\text { APTES grafting and incorporation of dual- } \\
\text { sized fillers enhanced the thermal conductiv- } \\
\text { ity of composites significantly. The thermal } \\
\text { conductivity of composites with dual-sized } \\
\text { surface-modified BN fillers reached } \\
0.68 \mathrm{~W} /(\mathrm{m} \cdot \mathrm{K}) \text { at } 41.08 \mathrm{wt} \% \mathrm{~h}-\mathrm{BN} \text { loading, } \\
\text { which was } 387 \% \text { more than that of pure cel- } \\
\text { lulosic fiber. }\end{array}$ & {$[30]$} \\
\hline $\begin{array}{l}\text { Polyimide (PI)/amino-BN, } \\
\text { PI/BN-ND, } \\
\text { Amino-BN = h-BN with } \\
\text { amino groups attached to } \\
\text { its surface, } \\
\text { BN-ND = h-BN nanodia- } \\
\text { mond hybrid filler }\end{array}$ & $\begin{array}{l}\text { h-BN, } \\
\text { BN-ND hybrid } \\
\text { filler. }\end{array}$ & $\begin{array}{l}\text { Amino group functionalization } \\
\text { of h-BN and fabrication of a } \\
\text { nano-micro hybrid filler con- } \\
\text { sisting of h-BN and nanodia- } \\
\text { mond. }\end{array}$ & $\begin{array}{l}\text { Both surface modification of h-BN fillers } \\
\text { and incorporation of hybrid fillers improved } \\
\text { the thermal conductivity of composites. The } \\
\text { highest thermal conductivity of the compos- } \\
\text { ites was } 0.98 \mathrm{~W} /(\mathrm{m} \cdot \mathrm{K})(5.2 \text { times that of PI). } \\
\text { It was achieved by incorporating } 40 \mathrm{wt} \% \text { hy- } \\
\text { brid filler (in a } 1: 10 \text { ratio of ND: modified } \\
\text { BN). }\end{array}$ & {$[59]$} \\
\hline $\begin{array}{l}\text { High-density polyethylene } \\
\text { (HDPE)/hexagonal boron } \\
\text { nitride (h-BN) nanocom- } \\
\text { posites }\end{array}$ & h-BN & $\begin{array}{l}\text { Surface modification of hexag- } \\
\text { onal boron nitride nanoparticles } \\
\text { (h-BN) via treatment with cold } \\
\text { ethylene plasma. }\end{array}$ & $\begin{array}{l}\text { Generally, all HDPE/h-BN nanocomposites } \\
\text { exhibited improved thermal conductivities } \\
\text { when compared with pure HDPE. Plasma } \\
\text { treated samples (treated at } 100 \mathrm{~W} \text { for } 5 \mathrm{~min} \text { ) } \\
\text { exhibited conductivity values that were } 97 \\
\text { and } 114 \% \text { higher than that of pure HDPE at } \\
8 \mathrm{wt} \% \text { and } 15 \mathrm{wt} \% \mathrm{~h}-\mathrm{BN} \text { content. }\end{array}$ & {$[60]$} \\
\hline $\begin{array}{l}\text { Epoxy resin-impregnated } \\
\text { insulation paper (RIP) com- } \\
\text { posites modified with } \\
\text { nano-h-BN }\end{array}$ & $\begin{array}{l}\text { Nano-hexago- } \\
\text { nal boron } \\
\text { nitride (nano- } \\
\text { h-BN) }\end{array}$ & $\begin{array}{l}\text { RIP composites were modified } \\
\text { with nano-h-BN }\end{array}$ & $\begin{array}{l}\text { A maximum heat conductivity of } \\
0.478 \mathrm{~W} /(\mathrm{m} \cdot \mathrm{K}) \text { was reached with nano-h-BN } \\
\text { modified RIP composites, which was } 139 \% \\
\text { more than that of unmodified RIP compos- } \\
\text { ites. }\end{array}$ & {$[61]$} \\
\hline
\end{tabular}

nanofiller were denoted as EP-BN. Thermal conductivity results showed the thermal conductivity of the EP-AgBN composites was greatly improved at higher nanofiller loadings (beyond $10 \mathrm{vol} \%$ ) as compared to that of EP-BN composites (see Figure 4a). A similar observation was also made with the thermal conductivity enhancement (TC-E) of the composites at higher nanofiller loadings (see Figure 4b). The thermal conductivity of EP-AgBN reached a maximum value of $2.14 \mathrm{~W} /(\mathrm{m} \cdot \mathrm{K})$ at a filler loading of $25 \mathrm{vol} \%$, which was almost twice that of EP-BN $(1.13 \mathrm{~W} /(\mathrm{m} \cdot \mathrm{K}))$. This indicated that the AgNPsBNNS nano-hybrid filler improved the thermal conductivity of epoxy more that the BNNS nanofiller. 

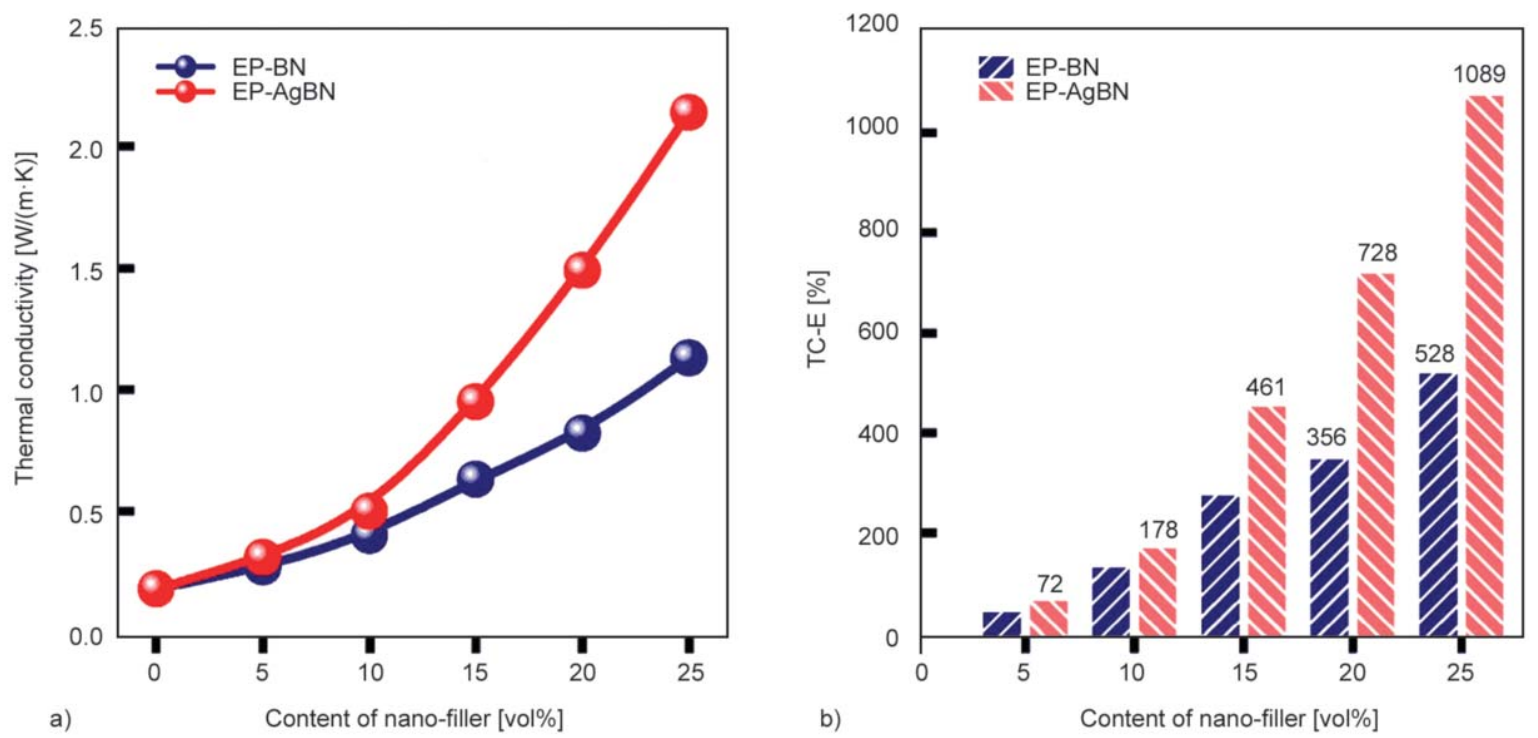

Figure 4. (a) Thermal conductivity versus nanofiller content plot of epoxy (EP)-boron nitride (BN) and epoxy (EP)-silver nanoparticle modified boron nitride $(\mathrm{AgB})$ and $(\mathrm{b})$ thermal conductivity enhancement(TC-E) versus nanofiller content plot of EP-BN and EP-AgBN [71] (MDPI open access).

Furthermore, a similar study by Zhang et al. [72] investigated the synergistic efficiency of positively charged boron nitride $(\mathrm{pBN})$ and negatively charged carbon nanotubes (nCNTs) hybrid fillers incorporated into a high-performance epoxy (EP) matrix. The results revealed that the thermal conductivity of pBN@nCNTs/EP composites could reach a value of $1.986 \mathrm{~W} /(\mathrm{m} \cdot \mathrm{K})$ with $50 \mathrm{wt} \%$ filler loading at a $10: 1$ mass ratio of pBN:nCNTs, which was 464 and 124\% higher than that of pure $\mathrm{EP}$ and $\mathrm{BN} / \mathrm{EP}$, respectively. This indicated that the incorporation of nCNTs particles into BN/EP composites was effective in increasing the thermal conductivity of the composites. Furthermore, the overall synergistic efficiency of the composites was larger than $1(f>1)$, which demonstrated an excellent synergistic effect of the nCNTs and $\mathrm{pBN}$ hybrid fillers in improving the thermal conductivity of the composites. The synergistic efficiency decreased with the increasing mass ratio of nCNTs and $\mathrm{pBN}$ hybrid fillers. This was attributed to the smaller content of carbon nanotubes in the co-fillers, which resulted in the isolation of some $\mathrm{pBN}$ fillers in the matrix. It is well-known that mixing different sizes (nano and micro or nanowire and nanosheets) of thermally conductive fillers can increase the probability of forming thermally conductive pathways. This is because the small-sized fillers can fill the gaps between the large-sized fillers, and the small nanosheets can be packed between the nanowires [69]. For example, Wu et al. [74] prepared thermally conductive ternary poly(vinylidene fluoride) (PVDF)based dielectric materials via the engineering of the filler networks of hexagonal boron nitride (h-BN) nanosheet and surface functionalized silicon carbide (f-SiC) nanowires. The synergistic effect of the h-BN nanosheets and $\mathrm{f}-\mathrm{SiC}$ nanowires enhanced the thermal conductivity of the composites. This is because the parallel-oriented $\mathrm{f}-\mathrm{SiC}$ nanowires were bridged by h-BN nanosheet networks. The highest thermal conductivity reached was $1.41 \mathrm{~W} /(\mathrm{m} \cdot \mathrm{K})$ which 5.9 times

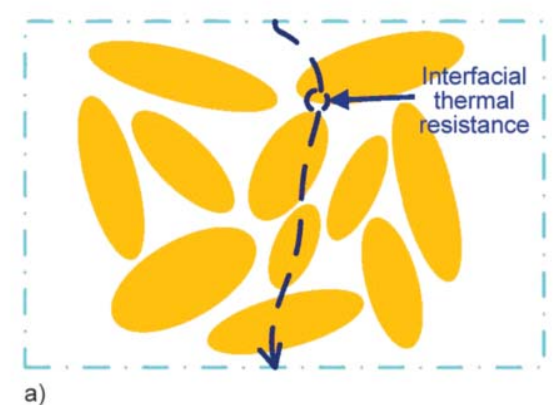

a)

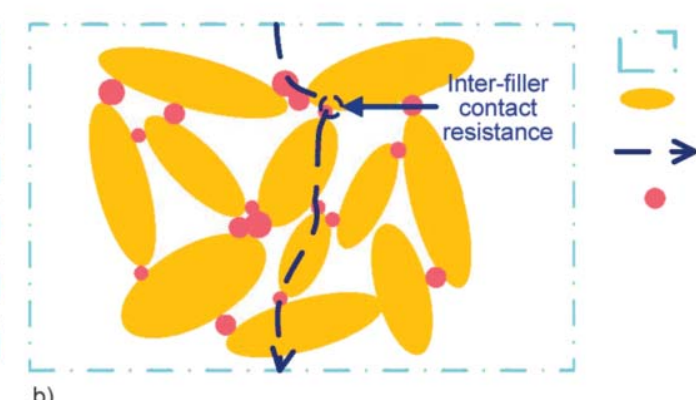

Polymer matrix

Boron nitride

Thermal transfer path

Silver nano-particles

Figure 5. Thermally conductive pathways of polymer nanocomposites (a) with no inter-filler networks and (b) consisting of inter-filler networks [71] (MDPI open access). 
that of neat PVDF. This thermal conductivity was achieved with ternary blends consisting of $20 \mathrm{wt} \%$ h-BN nanosheets and $26 \mathrm{wt} \% \mathrm{f}-\mathrm{SiC}$ nanowires. In another study, Wu et al. [71] illustrated the formation of thermal pathways between silver nanoparticles (AgNPs) and boron nitride nanosheets (BNNSs) in an epoxy nanocomposite (see Figure 5). The illustration showed that the main thermal transfer paths were formed by BNNSs in the nanocomposites and the AgNPs connected the BNNSs as a 'thermal bridge', which resulted in the formation of inter-filler thermal networks in the polymer composites. Nanocomposites consisting of the inter-filler networks had a higher thermal conductivity than those without a network.

Table 6. Selective studies on the hybrid fillers for enhancing the thermal conductivity of the composites.

\begin{tabular}{|c|c|c|c|}
\hline Composites system & Hybrid fillers & $\begin{array}{l}\text { Effect of hybrid fillers on thermal conductivity of the composites } \\
\qquad[\mathrm{W} /(\mathrm{m} \cdot \mathrm{K})]\end{array}$ & References \\
\hline $\begin{array}{l}\text { Boron nitride nanosheets (BNNs)- } \\
\text { graphene nanosheets (GNs)-poly- } \\
\text { tetrafluoroethylene (PTFE) compos- } \\
\text { ites }\end{array}$ & $\begin{array}{l}\text { BNNs and } \\
\text { GNs }\end{array}$ & $\begin{array}{l}\text { The results revealed that the thermal conductivity of the BNNs-GNPs- } \\
\text { PFTE composites reached a value of } 1.41 \mathrm{~W} /(\mathrm{m} \cdot \mathrm{K}) \text { which was higher } \\
\text { than that of BNNs-PFTE composite }(0.74 \mathrm{~W} /(\mathrm{m} \cdot \mathrm{K}) \text { and PFTE poly- } \\
\text { mer }(0.32 \mathrm{~W} /(\mathrm{m} \cdot \mathrm{K}) \text { at the same filler content }(\mathrm{BNNs}-24 \mathrm{wt} \% \text { and } \\
\text { GNPs- } 1 \mathrm{wt} \%) \text {. This indicated that the incorporation of even a small } \\
\text { content of GNPs }(1 \mathrm{wt} \%) \text { into the BNNs-PFTE composites signifi- } \\
\text { cantly improved the thermal conductivity of the composites. }\end{array}$ & {$[73]$} \\
\hline $\begin{array}{l}\text { Epoxy (EP)-boron nitride-silver } \\
\text { (AB) nanocomposites }\end{array}$ & $\mathrm{Ag}$ and $\mathrm{BN}$ & $\begin{array}{l}\text { The nano-hybrid filler loading of } 25 \mathrm{vol} \% \text { significantly increased the } \\
\text { thermal conductivity of the EP-AB nanocomposites to } 2.14 \mathrm{~W} /(\mathrm{m} \cdot \mathrm{K}) \text {. } \\
\text { This improvement was due to the silver bridge connection between } \\
\text { the boron nitride nanosheets (BNNS) and, thus, forming the thermal } \\
\text { conduction channels in the composites. }\end{array}$ & {$[74]$} \\
\hline $\begin{array}{l}\text { Ultra-high-molecular-weight poly- } \\
\text { ethylene (UHMWPE)/boron nitride } \\
\text { particle (BNp), boron nitride sheet } \\
\text { (BNs), and UHMWPE/ } \\
\text { (BN+MWCNT) hybrid filler com- } \\
\text { posites }\end{array}$ & $\begin{array}{l}\text { BNp, } \\
\text { BNs and } \\
\text { MWCNTs }\end{array}$ & $\begin{array}{l}\text { The thermal conductivity of the UHMWPE/(BNs+MWCNT) com- } \\
\text { posite was increased to } 1.641 \mathrm{~W} /(\mathrm{m} \cdot \mathrm{K}) \text {, and that of the UHMWPE/ } \\
(\mathrm{BNp}+\mathrm{MWCNT}) \text { composite was also increased to } 1.533 \mathrm{~W} /(\mathrm{m} \cdot \mathrm{K}) \text { at } \\
50 \mathrm{wt} \% \text { hybrid filler loading. }\end{array}$ & {$[63]$} \\
\hline $\begin{array}{l}\text { Cellulose nanofibers (CNFs)/boron } \\
\text { nitride nanotubes (BNNTs) compos- } \\
\text { ites }\end{array}$ & $\begin{array}{l}\text { BNNTs and } \\
\mathrm{Ag}\end{array}$ & $\begin{array}{l}\text { The thermal conductivity of the Ag-BNNTs/CNF was higher than that } \\
\text { of the BNNTs/CNF composites. For instance, at } 25 \mathrm{wt} \% \text { BNNTs load- } \\
\text { ing, the thermal conductivity of the Ag-BNNTs/CNF composites was } \\
20.9 \mathrm{~W} /(\mathrm{m} \cdot \mathrm{K}) \text { whilst that of the BNNTs/CNF composites was } \\
12.9 \mathrm{~W} /(\mathrm{m} \cdot \mathrm{K}) \text {. }\end{array}$ & {$[68]$} \\
\hline $\begin{array}{l}\text { Boron nitride }(\mathrm{BN}) / \text { multi-walled } \\
\text { carbon nanotubes } \\
(\mathrm{MWCNTs}) / \text { polyphenylene sulfide } \\
\text { (PPS) composites }\end{array}$ & $\begin{array}{l}\text { BN and } \\
\text { MWCNTs }\end{array}$ & $\begin{array}{l}\text { It was reported that the thermal conductivity of the BN-MWCNTs- } \\
\text { PPS composites was almost the same as that of BN/PPS composites. } \\
\text { This indicated that the synergistic effect between the BN and MWCNTs } \\
\text { was not effective with the melt-mixing method. }\end{array}$ & {$[75]$} \\
\hline $\begin{array}{l}\text { Micro-boron nitride/nano- } \mathrm{Al}_{2} \mathrm{O}_{3} / \\
\text { epoxy composites (micro-nano- } \\
\text { composites) }\end{array}$ & $\begin{array}{l}\text { Micro- } \mathrm{BN} \text { and } \\
\text { nano- } \mathrm{Al}_{2} \mathrm{O}_{3}\end{array}$ & $\begin{array}{l}\text { The thermal conductivity of the hybrid composites reached a value of } \\
1.182 \mathrm{~W} /(\mathrm{m} \cdot \mathrm{K}) \text { with } 22.5 \mathrm{wt} \% \mathrm{BN} \text { and } 7.5 \mathrm{wt} \% \mathrm{Al}_{2} \mathrm{O}_{3} \text {, which was } \\
700 \% \text { higher than that of a neat epoxy resin }(0.148 \mathrm{~W} /(\mathrm{m} \cdot \mathrm{K}))\end{array}$ & {$[76]$} \\
\hline $\begin{array}{l}\text { Boron nitride/aluminium nitride } \\
\text { (AIN)/epoxy composites }\end{array}$ & $\mathrm{BN}$ and $\mathrm{AIN}$ & $\begin{array}{l}\text { The thermal conductivity of hybrid composites reached a value of } \\
2.4 \mathrm{~W} /(\mathrm{m} \cdot \mathrm{K}) \text { at } 40 \% \text { hybrid BN-AIN filler contents, which was much } \\
\text { higher than that of BN/EP }(1.3 \mathrm{~W} /(\mathrm{m} \cdot \mathrm{K})) \text { and } \mathrm{AlN} / \mathrm{EP} \text { composites } \\
(1.4 \mathrm{~W} /(\mathrm{m} \cdot \mathrm{K})) \text {, respectively. This high enhancement of the thermal } \\
\text { conductivity was attributed to the synergistic effect of BN and AlN } \\
\text { particles. }\end{array}$ & {$[77]$} \\
\hline $\begin{array}{l}\text { Boron nitride nanosheets } \\
\text { (BNNS)/graphene oxide nanosheets } \\
\text { (GO)/poly(vinyl alcohol) (PVA) } \\
\text { composites }\end{array}$ & $\begin{array}{l}\text { BNNS and } \\
\text { GO }\end{array}$ & $\begin{array}{l}\text { The incorporation of } 0.8 \mathrm{wt} \% \mathrm{GO} \text { particles in the PVA/ } 0.8 \mathrm{BNNS} \text { com- } \\
\text { posites improved the in-plane thermal conductivity to } 9.90 \mathrm{~W} /(\mathrm{m} \cdot \mathrm{K}) \\
\text { which was approximately } 38 \text { times that of the cross-plane conductiv- } \\
\text { ity. The GO nanosheets improved the distribution of the boron nitride } \\
\text { nanosheets, which resulted in the significant enhancement of in-plane } \\
\text { thermal conductivity. }\end{array}$ & {$[78]$} \\
\hline $\begin{array}{l}\text { Boron nitride/aluminium } \\
\text { nitride/ultra-high multi weight poly- } \\
\text { ethylene (UHMWPE) composites }\end{array}$ & $\mathrm{BN}$ and $\mathrm{AIN}$ & $\begin{array}{l}\text { The thermal conductivity of the segregated hybrid fillers }(\mathrm{BN}+\mathrm{AIN}) / \\
\text { UHMWPE composite reached a value of } 6.44 \mathrm{~W} /(\mathrm{m} \cdot \mathrm{K}) \text { at the ratio of } \\
3: 1 \mathrm{BN} \text { : AIN, which was } 23 \text { and } 321 \% \text { higher than that of individual } \\
\text { filler composites (BN/UHMWPE composite and AIN/UHMWPE } \\
\text { composite) at } 50 \mathrm{wt} \% \text { filler content. This observation showed that the } \\
\text { low thermal conductivity of pure UHMWPE polymer }(0.39 \mathrm{~W} /(\mathrm{m} \cdot \mathrm{K})) \\
\text { was successfully enhanced more with the incorporation of hybrid } \\
\text { fillers (BN+AIN) than with individual fillers. }\end{array}$ & {$[64]$} \\
\hline
\end{tabular}


This is because the inter-filler contact resistance is less than the interfacial thermal resistance between matrix and filler. Table 6 summarizes the selective studies on the incorporation of conductive hybrid fillers into polymer matrices for enhancing the thermal conductivity of BN-polymer composites.

\section{The effect of orientation of boron nitride on the thermal conductivity of the composites}

It has been observed that the orientation of fillers has an effect on improving thermal conductivity and forming excellent thermally conductive networks [79-83]. Controlling the orientation of fillers in a polymer matrix is crucial for increasing the thermal conductivity enhancement of composites [83]. Liu et al. [79] investigated the thermal conductivity of random and oriented BN/PDMS composites as well as the thermal conductivity of random and oriented boron nitride $(\mathrm{BN}) /$ alumina $\left(\mathrm{Al}_{2} \mathrm{O}_{3}\right) /$ polydimethylsiloxane (PDMS) composites. The thermal conductivity of the oriented composites is anisotropic. The results obtained by Liu et al. [79] were focused on the thermal conductivity of composites oriented in the in-plane orientation direction. It was reported that the filler oriented-BN/ PDMS and oriented$\mathrm{BN} / \mathrm{Al}_{2} \mathrm{O}_{3} / \mathrm{PDMS}$ composites exhibited slightly higher thermal conductivities in comparison to random $\mathrm{BN} / \mathrm{PDMS}$ and random $\mathrm{BN} / \mathrm{Al}_{2} \mathrm{O}_{3} / \mathrm{PDMS}$ composites, indicating that the in-plane orientation of the $\mathrm{BN}$ fillers improved the thermal conductivities of the polymer composites. Furthermore, it was also reported that the in-plane orientation of hybrid fillers greatly improved the thermal conductivity of the composites as compared to the in-plane orientation of

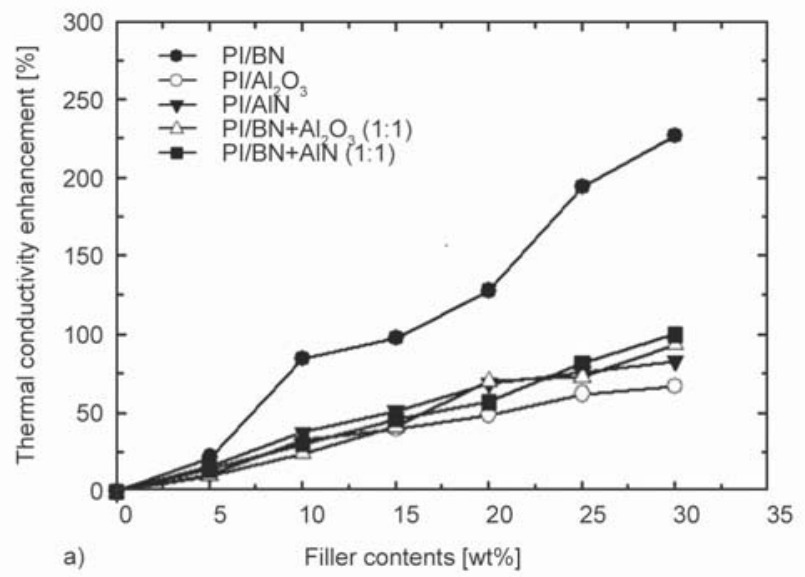

individual fillers. Song et al. [66] investigated the synergistic effects of different ceramic fillers on thermally conductive polyimide composite films. The thermally conductive composite films were prepared using an anisotropic boron nitride (BN) and hybrid filler system combined with spherical aluminum nitride $(\mathrm{AlN})$ or aluminum oxide $\left(\mathrm{Al}_{2} \mathrm{O}_{3}\right)$ particles in a polyimide matrix. The hybrid system led to a decrease in the through-plane thermal conductivity and an increase in the in-plane thermal conductivity of the BN composite. The highest values were recorded along the in-plane direction of the films containing hybrid fillers as shown in Figure 6. This was ascribed to the horizontal alignment and anisotropy of $\mathrm{BN}$.

Chen et al. [82] prepared boron nitride nanosheets (BNNS)/cellulose nanofiber (CNF) shear-oriented and self-oriented film composites. It was reported that the in-plane thermal conductivity of BNNS/CNF shear-oriented films at $50 \mathrm{wt} \%$ filler loading was enhanced to $24.66 \mathrm{~W} /(\mathrm{m} \cdot \mathrm{K})$ as compared to that of pure $\mathrm{CNF}$ polymer $(2.04 \mathrm{~W} /(\mathrm{m} \cdot \mathrm{K}))$. However, for the self-oriented films, the thermal conductivity was improved to $8.61 \mathrm{~W} /(\mathrm{m} \cdot \mathrm{K})$ at the same filler loading. This indicated that the shear-oriented films gave better results compared to self-organized films. Cao et al. [81] investigated the thermal conductivity of the oriented-BNNs/polyimide (PI) composites. The thermal conductivity of oriented-BNNs/PI composites at filler loading of $12.4 \mathrm{vol} \%$ BNNs was significantly increased to $4.25 \mathrm{~W} /(\mathrm{m} \cdot \mathrm{K})$ as compared to that of pure PI polymer $(0.85 \mathrm{~W} /(\mathrm{m} \cdot \mathrm{K}))$ and randomBNNs/PI composite $(1.3 \mathrm{~W} /(\mathrm{m} \cdot \mathrm{K}))$. This indicated that the thermal conductivity of oriented-BNNs/PI composites increased by 69 and $80 \%$ as compared to the thermal conductivities of random-BNNs/PI

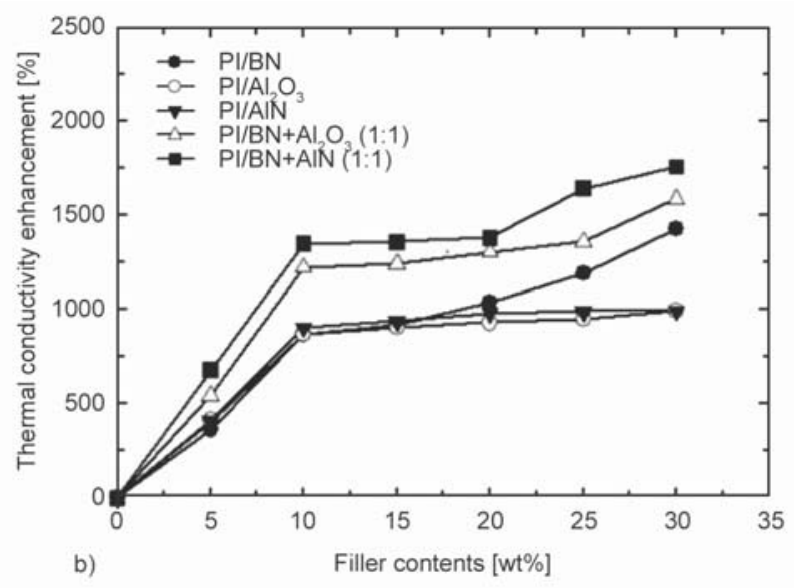

Figure 6. Thermal conductivity versus filler content plots of the composite films obtained along the (a) through-plane and (b) in-plane directions [66] (MDPI open access). 
composites and pure PI polymer. Kim and Kim [83] investigated the use of an external magnetic field to induce vertical filler alignment along the direction of heat transport in boron nitride/epoxy composites. The thermal conductivity of the vertically aligned BN-EP composites was significantly increased from 1.765 to $3.445 \mathrm{~W} /(\mathrm{m} \cdot \mathrm{K})$ at $30 \mathrm{vol} \%$ filler loading. This was a 1.96-fold increase when compared to the thermal conductivity of random BN-EP composites.

\section{Modeling of thermal conductivity of boron nitride-polymer composites}

Due to the increasing demand for high thermal conductivity materials in thermal management applications, numerous models such as Maxwell model, Rayleigh model, McKenzie model, Bruggeman model, Hashin-Shtrikman model, Voigt-Reuss (series and parallel model), modified effective medium approximation (EMA) model, Lewis-Nielsen model, and Agari model have been used over the years to predict the thermal conductivity of the fabricated $\mathrm{BN}$ polymer composites and their conductive hybrid composites [9, 14, 58, 73, 84-88]. Combining experimental data and theoretical calculations (models) is necessary because it makes it easier to understand and analyze the effectiveness of the thermal conductivity in polymer composites. For example, Cai et al. [73] used the modified effective medium theory (EMT) to analyze the synergistic effect between GNs and BNNs on the thermal conductivity of the composites. The used EMT model took into account factors such as the filler size and orientation as well as the thermal resistance at the filler-matrix interface. The effective thermal conductivity $\left(K_{\text {eff }}\right)$ of the boron nitride-polytetrafluoroethylene (PTFE) (BP) composites was calculated using Equation (3):

$K_{\text {eff }}=K_{\mathrm{m}} \frac{3+2\left(f_{\mathrm{BN}}-f_{\mathrm{C}}\right)^{\mathrm{t}}\left(\frac{K_{\mathrm{BN}}^{\mathrm{eff}}}{K_{\mathrm{m}}}\right)}{3-f_{\mathrm{BN}}}$

where according to the authors, $K_{\mathrm{m}}$ represented the thermal conductivity (TC) of the matrix. $f_{\mathrm{BN}}$ represented the BNNs filler content. $f_{\mathrm{C}}$ represented the critical filler content which is equal 0.001 . The parameter, $\mathfrak{i}$ represented filler dispersion in the PTFE matrix. $t=1$ means that the filler is dispersed randomly in the matrix, and $t>1$ means that the filler is inhomogeneously dispersed in PTFE. Generally, when the value of $t$ is increased, the filler dispersion in the matrix becomes worse. The reasonable bounds for parameter $t$ would be $1<t<2$. The EMT model suggests that improving the value of $t$ and reducing thermal resistance $\left(R_{\mathrm{K}}\right)$ at the filler-matrix interface facilitates phonon transmittance and hence improves the effective thermal conductivity ( $\left.K_{\text {eff }}\right)$.

When hybrid fillers such as BNNs and GNs were taken into account, the EMT equation in Equation (3) was changed by the authors to the Equation (4):

$K_{\mathrm{eff}}=\frac{3+2\left(f_{\mathrm{BN}}-f_{\mathrm{C}}\right)^{\mathrm{t}}\left(\frac{K_{\mathrm{BN}}^{\mathrm{eff}}}{K_{\mathrm{m}}}\right)+2 f_{\mathrm{GNs}}\left(\frac{K_{\mathrm{GN}}^{\mathrm{eff}}}{K_{\mathrm{m}}}\right)}{3-\left(f_{B N}+f_{\mathrm{GNs}}\right)}$

where according to the authors, $f_{\mathrm{GNs}}$ represented GNs content. $K_{\mathrm{BN}}^{\text {eff }}$ and $K_{\mathrm{GNS}}^{\text {eff }}$ represented the effective TCs of BNNs and GNs in the PTFE matrix. $K_{\mathrm{BN}}^{\text {eff }}$ and $K_{\mathrm{GNS}}^{\mathrm{eff}}$ are defined by the Equations (5) and (6):

$K_{\mathrm{BN}}^{\mathrm{eff}}=\frac{K_{\mathrm{BN}}}{\frac{2 R_{\mathrm{K}} K_{\mathrm{BN}}}{l_{\mathrm{BN}}}+1}$

$K_{\mathrm{GNs}}^{\mathrm{eff}}=\frac{K_{\mathrm{GNs}}}{\frac{2 R_{\mathrm{K}} K_{\mathrm{GNs}}}{l_{\mathrm{GNs}}}+1}$

where according to the authors, $K_{\mathrm{BN}}$ and $K_{\mathrm{GNs}}$ represented the TCs of BNNs and GNs. $l_{\mathrm{BN}}$ and $l_{\mathrm{GNs}}$ represented the lengths of BNNs and GNs, which can be obtained from SEM images. $R_{\mathrm{K}}$ represented thermal resistance at the fillers-PTFE matrix.

In this study, the $t$ and $R_{\mathrm{K}}$ values in Equations (3) and (5) were set as 1.43 and $7 \cdot 10^{-8} \mathrm{~m}^{2} \cdot \mathrm{K} / \mathrm{W}$ for BP composites. It was observed by the authors that the experimental thermal conductivity values of the BP composites fitted well with their theoretical values. For BGP composites, the $t$ and $R_{\mathrm{K}}$ values in Equations (4) and (6) were also like those of BP composites. At these values, the theoretical thermal conductivity values of the BGP composites agreed well with the experimental values. However, when the filler content was above $10 \%$, the theoretical values were much less than the measured values. Similar observations were reported by Goldin et al. [86] when using three models (Maxwell, Lewis-Nielsen, and Agari-Uno) to increase the thermal conductivity of photopolymerizable composites. Both models (Lewis-Nielsen and Agari-Uno) fitted well with the experimental results, providing a much more improved thermal conductivity, whereas the Maxwell model was ineffective because the predicted values of thermal conductivity were much less in comparison with experimental results. Song et al. [66] used the Lewis-Nielsen and 
modified Lewis-Nielsen theoretical prediction models to predict the in-plane thermal conductivity behavior of thermally conductive polyimide (PI) composite films. A perfect fit between the experimental and theoretical data in both models was only obtained for the single-filler system using BN (PI/BN) (Figure 7). The other composites showed underestimated values (see Figure 7).

Furthermore, in another study by Pan et al. [84] the effect of h-BN's anisotropy in h-BN/PTFE composites was analyzed using the Maxwell model. It was reported that when the filler loading was below $20 \mathrm{vol} \%$, the experimental thermal conductivity was basically the same as the predicted values by the Maxwell model (through-plane), showing that there was a good agreement between the two results. However, at higher filler loading above $20 \mathrm{vol} \%$, the effective experimental thermal conductivity was increased rapidly, showing higher values compared to predicted values by the Maxwell model (in-plane). Therefore, this proved that the measured experimental thermal conductivity gave better results compared to predicted values by the Maxwell model (in-plane and through-plane). However, when the modified effective medium approximation (EMA) model was used, the effective thermal conductivity of randomly oriented h-BN was much higher than the measured experimental values. Zhang et al. [14] used the Agari model to predict the thermal conductivity of $\mathrm{PE} / \mathrm{BN}$ composites. There was an increase in thermal conductivity due to the formation of a thermally conductive network formed by fillers with respect to the Agari model's results. The modification of BN surface particles and the incorporation of a compatibilizer (i.e., PE-g-MAH) also contributed to the building of thermally conductive pathways. However, the incorporation of the compatibilizer was found to be more effective in enhancing the thermal conductivity than the modification of BN surface particles. The comparisons between experimental results and theoretical models of selected studies on BN-polymer composites are summarized in Table 7.

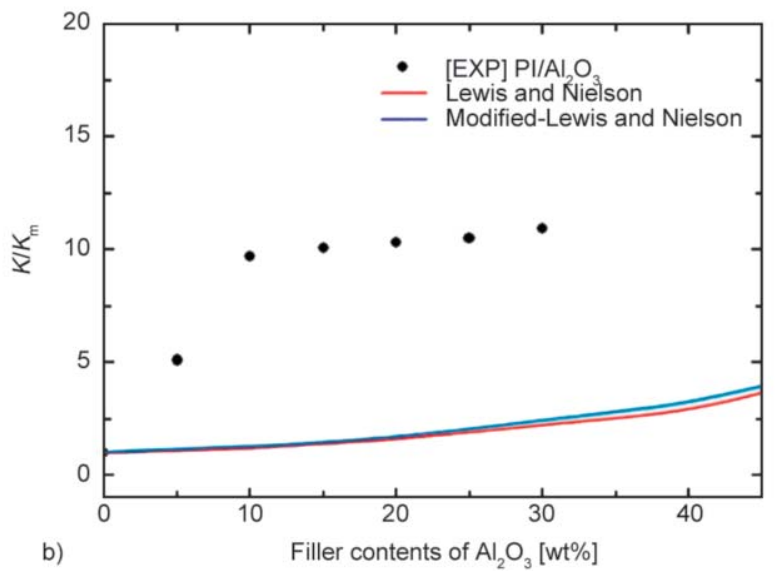

b)
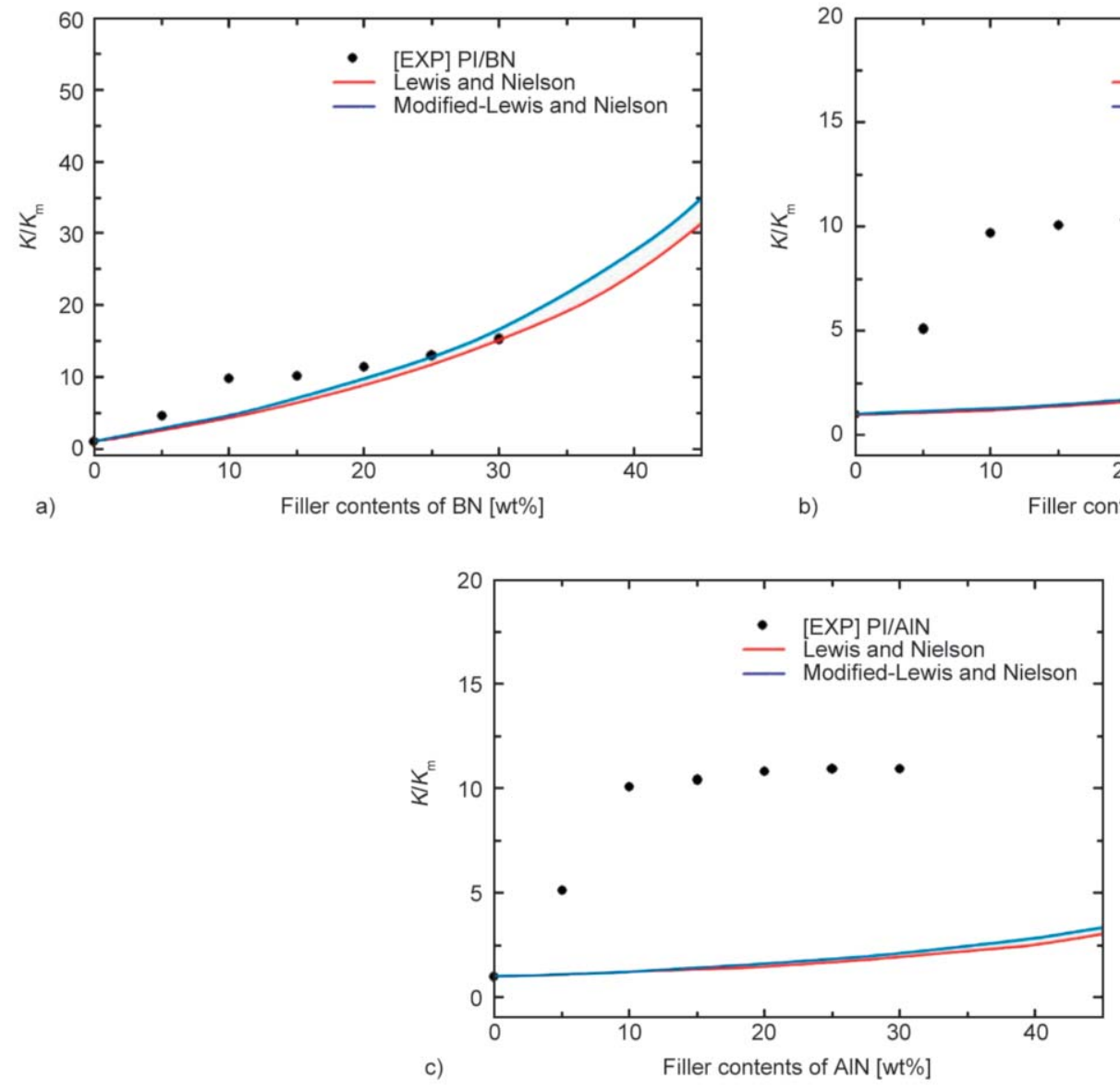

Figure 7. Experimental and theoretical thermal conductivity predicted with the regular and modified Lewis-Nielsen models for the (a) polyimide (PI)/BN; (b) $\mathrm{PI} /$ (aluminum oxide) $\mathrm{Al}_{2} \mathrm{O}_{3}$; and (c) $\mathrm{PI} /$ (aluminum nitride) AlN composite films [66] (MDPI open access). 
Table 7. Selective studies comparing the thermal conductivity of the measured experimental values and the predicted values by models.

\begin{tabular}{|c|c|c|c|}
\hline System & Model used & $\begin{array}{c}\text { Findings on measured experimental results vs. predicted values of } \\
\text { thermal conductivity by models }\end{array}$ & References \\
\hline $\begin{array}{l}\text { Boron nitride/poly- } \\
\text { imide composites }\end{array}$ & $\begin{array}{l}\text { Modified Hashin-Shtrikman } \\
\text { model }\end{array}$ & $\begin{array}{l}\text { The calculated thermal conductivity values of the modified Hashin- } \\
\text { Shtrikman model were higher than the measured experimental values. } \\
\text { This was an indication that modifying the BN particle surface has the } \\
\text { potential for improving the thermal conductivity of the BN/polyimide } \\
\text { composites. }\end{array}$ & {$[58]$} \\
\hline $\begin{array}{l}\text { Graphene@boron } \\
\text { nitride/epoxy com- } \\
\text { posites (GBN/epoxy } \\
\text { composites) }\end{array}$ & Lewis-Nielson model & $\begin{array}{l}\text { Upon comparison of the experimental results with those of the Lewis- } \\
\text { Nielson model, it was found that the thermal conductivity was improved } \\
\text { to higher values for GBN1/epoxy composites in both results. However, } \\
\text { with the GBN10/ and GBN50/epoxy composites, low thermal conduc- } \\
\text { tivity values were observed. This indicated that GBN1 particle was more } \\
\text { valuable to enhance thermal conductivity than both GBN10 and GBN50 } \\
\text { particles (The numbers next to GBN, i.e. GBN1, GBN10, and GBN50 } \\
\text { represent the weight ratios of BNNSs and graphene in the GBN hybrid } \\
\text { fillers, GBN1 ( } 250 \mathrm{mg} \text { of BNNSs and } 250 \mathrm{mg} \text { of graphene), GBN10 } \\
(500 \mathrm{mg} \text { of BNNSs and } 50 \mathrm{mg} \text { of graphene), GBN50 (500 mg of BNNSs } \\
\text { and } 10 \mathrm{mg} \text { of graphene)). Since the Lewis-Nielsen model equation used } \\
\text { was meant to predict the thermal conductivity for a composite with one } \\
\text { type of filler, the maximum packing fraction of the fillers }\left(\varphi_{\mathrm{m}}\right) \text { in the } \\
\text { equation was assumed to be } 0.52 \text { in order to predict the thermal conduc- } \\
\text { tivity of the GBN hybrid filler composites. This was based on the fact } \\
\text { that the GBN hybrid nanoparticles were three-dimensional randomly } \\
\text { packed in the epoxy matrix and that they were constructed using a two- } \\
\text { dimensional filler of graphene and BNNSs. }\end{array}$ & [87] \\
\hline $\begin{array}{l}\text { BN/epoxy compos- } \\
\text { ites }\end{array}$ & Agari-Uno model & $\begin{array}{l}\text { The Agari-Uno model results fitted well with the experimental results. } \\
\text { This indicated that the polysilazane (PSZ) coating and 3-glycidy- } \\
\text { loxypropyltri-methoxysilane (GPTMS) grafting used were great methods } \\
\text { for enhancing the thermal conductivity. }\end{array}$ & [89] \\
\hline $\begin{array}{l}\text { Polypropylene/boron } \\
\text { nitride composites }\end{array}$ & Hatta and Taya model & $\begin{array}{l}\text { The experimental data for series } 1(45 \mu \mathrm{m} \mathrm{BN}) \text { matched well with the } \\
\text { in-plane calculations of the Hatta/Taya model giving higher values of } \\
\text { thermal conductivity. However, at higher filler loading above } 50 \mathrm{vol} \% \text {, the } \\
\text { experimental results had higher values of thermal conductivities than } \\
\text { that of the Hatta/Taya model. As for out-of-plane results, both experi- } \\
\text { mental and calculations of the Hatta/Taya model gave much lower ther- } \\
\text { mal conductivity compared to in-plane calculations. }\end{array}$ & [89] \\
\hline \multirow[t]{2}{*}{$\begin{array}{l}\text { Isotactic polypropy- } \\
\text { lene/hexagonal } \\
\text { boron nitride com- } \\
\text { posites }\end{array}$} & Maxwell-Garnett model & $\begin{array}{l}\text { It was observed that the results of the Maxwell-Garnett model fitted very } \\
\text { well with the experimental data. This indicated that the addition of male- } \\
\text { ic anhydride grafted PP (MAPP) enhanced thermal conductivity a little } \\
\text { higher compared to composites without MAPP. }\end{array}$ & [34] \\
\hline & $\begin{array}{l}\text { Agari and Maxwell-Eucken } \\
\text { models }\end{array}$ & $\begin{array}{l}\text { It was reported that the thermal conductivity results calculated with the } \\
\text { Agari model were very close to the results calculated with the Maxwell- } \\
\text { Eucken model at the filler content below } 20 \mathrm{wt} \% \text {. However, when the } \\
\text { filler content was increased, the predicted thermal conductivity by Agari } \\
\text { was also increased rapidly, which indicated that conductive networks } \\
\text { were formed in the composites. Similar behavior was observed with the } \\
\text { experimental results. }\end{array}$ & {$[90]$} \\
\hline $\begin{array}{l}\text { Epoxy/boron nitride } \\
\text { composites }\end{array}$ & Lewis and Nielson model & $\begin{array}{l}\text { Lewis and Nielson modified the Halpin-Tsai equation for the thermal con- } \\
\text { ductivity of the polymer composites. As the boron nitride content in- } \\
\text { creased, the experimental results were very much close to the predicted } \\
\text { results by Lewis and Nielson model on the in-plane thermal conduction. } \\
\text { However, when the BN content was further increased, the experimental } \\
\text { results deviated from the predicted results based on the in-plane direction. }\end{array}$ & {$[91]$} \\
\hline $\begin{array}{l}\text { Ultra-high-molecular- } \\
\text { weight polyethylene/ } \\
\text { (boron nitride }+ \\
\text { multi walled carbon } \\
\text { nanotubes) compos- } \\
\text { ites }\end{array}$ & $\begin{array}{l}\text { Maxwell-Eucken and } \\
\text { Bruggeman models }\end{array}$ & $\begin{array}{l}\text { It was reported that the experimental results reflected higher thermal } \\
\text { conductivity values than the predicted models, especially for the } \\
\text { Maxwell model, which showed the lowest thermal conductivity values. } \\
\text { This was because the Maxwell model does not consider the mutual in- } \\
\text { teraction between filler particles, whereas the Bruggeman model was } \\
\text { more suitable for this experiment because it considered the effect of the } \\
\text { neighboring fillers. Hence it was observed that the Bruggeman model } \\
\text { predicted higher thermal conductivity than the Maxwell model even } \\
\text { though the experimental results were higher than those of both models. }\end{array}$ & {$[63]$} \\
\hline
\end{tabular}




\section{Mechanical properties of boron nitride- polymer based composites}

A lot of studies [93-96] have reported on the mechanical properties of boron nitride polymer-based composites. Generally, it was observed from the studies that the functionalization of $\mathrm{BN}$, the content of $\mathrm{BN}$, size of BN, shape, type of BN, and synergy of BN with other fillers had an effect on the overall mechanical properties of the resultant composites. In most cases, it was reported that the functionalized BN flakes showed better mechanical properties than the unmodified BN flakes. Öner et al. [92] investigated the mechanical properties of the $\mathrm{BN}$ reinforced poly (3-hydroxybutyrateco-3-hydroxyvalerate) (PHBV) composites. In this study, BN with a content ranging from 0.5 to $3 \mathrm{wt} \%$ and different shapes (i.e., flake type $\mathrm{BN}$ and hexagonal disk type $\mathrm{BN}$ ) were incorporated into the PHBV matrix through an extruder. The two types of boron nitride were modified by silanizing agent in the form of octyltriethoxysilane (OTES) in order to improve the interface between the conductive filler and polymer matrix. The addition of a low content silanized hexagonal boron nitride (OSBN), i.e., $0.5 \mathrm{wt} \%$ had no effect on the young modulus, while the incorporation of $2 \mathrm{wt} \%$ OSBN showed the highest young modulus (Figure 8a) when compared with all contents employed in this study, with $8 \%$ enhancement in stiffness. Furthermore, in case of the silanized flake boron nitride (OSFBN) showed that the optimum content in this type of BN was $1 \mathrm{wt} \%$, with the highest Young's modulus (Figure 8b) and tensile strength being obtained at this content.

These results indicated that there was a better dispersion of the boron nitride at low content i.e. 1 and $2 \mathrm{wt} \%$, irrespective of the BN type, while inhomogeneous dispersion of BN was observed at $3 \mathrm{wt} \%$,

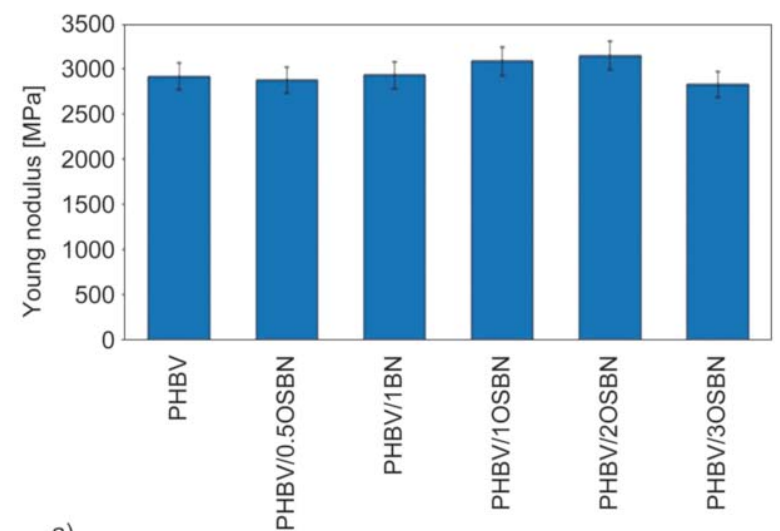

which deteriorated the mechanical properties. The obtained experimental results in this system [92] were compared with two theoretical models, i.e., Hui-Shia and Halpin-Tsai models. The description of the Halpin-Tsai model is based on the shape, the volume fraction of the filler, Young's modulus of reinforcement, and the matrix, while the Hui-Shia model was utilized on the assumption that there is a complete interfacial bonding in a composite system consisting of a filler and matrix. The Halpin-Tsai equation (Equations (7) to (9)) with randomly oriented fillers and Hui-Shia equation (Equations (10) to (13)) with platelets fillers are shown below, with their plots reported in Figure 9:

$$
\begin{aligned}
& \frac{E_{\mathrm{c}}}{E_{\mathrm{m}}}=\frac{3}{8}\left(\frac{1+\xi \eta_{\mathrm{L}} \phi_{\mathrm{f}}}{1-\eta_{\mathrm{L}} \phi_{\mathrm{f}}}\right)+\frac{5}{8}\left(\frac{1+2 \eta_{\mathrm{T}} \phi_{\mathrm{f}}}{1-\eta_{\mathrm{T}} \phi_{\mathrm{f}}}\right) \\
& \eta_{\mathrm{L}}=\frac{\left(\frac{E_{\mathrm{f}}}{E_{\mathrm{m}}}\right)-1}{\left(\frac{E_{\mathrm{f}}}{E_{\mathrm{m}}}\right)+\xi} \\
& \eta_{\mathrm{T}}=\frac{\left(\frac{E_{\mathrm{f}}}{E_{\mathrm{m}}}\right)-1}{\left(\frac{E_{\mathrm{f}}}{E_{\mathrm{m}}}\right)+2} \\
& \frac{E_{\mathrm{c}}}{E_{\mathrm{m}}}=\frac{1-\frac{\phi_{\mathrm{f}}}{4}\left(\frac{1}{\xi}+\frac{3}{\xi+\Lambda}\right)}{\xi_{\mathrm{f}}} \\
& \xi=\phi_{\mathrm{f}}+\frac{E_{\mathrm{m}}}{E_{\mathrm{f}}-E_{\mathrm{m}}}+3\left(-\phi_{\mathrm{f}}\right)\left(\frac{(1-g) \alpha^{2}-\frac{g}{2}}{\alpha^{2}-1}\right) \\
& g=\frac{\pi}{2} \alpha \\
& \Lambda=\left(1-\phi_{\mathrm{f}}\right)\left(\frac{3\left(\alpha^{2}+0.25\right) g-2 \alpha^{2}}{\alpha^{2}-1}\right)
\end{aligned}
$$

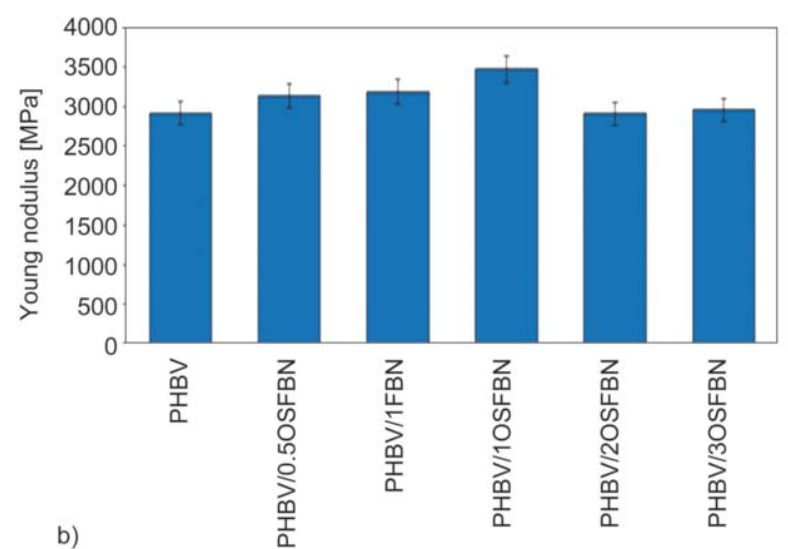

Figure 8. Young's modulus values of (a) PHBV/BN and (b) PHBV/FBN based nanocomposites [92] (MDPI open access). 
From the models, the symbols $E_{\mathrm{c}}, E_{\mathrm{m}}$, and $E_{\mathrm{f}}$ stand for Young's modulus of the composite, matrix, and filler, sequentially. The symbols $\eta_{\mathrm{L}}$ and $\eta_{\mathrm{T}}$ (from Halpin-Tsai model viz Equation (7)) are defined as the functions of the modulus of the filler $\left(E_{\mathrm{f}}\right)$ as well as the modulus of the matrix $\left(E_{\mathrm{m}}\right)$. $\phi_{\mathrm{f}}$ from the models above stands for the volume fraction of the filler in the composite, and it is defined by Equation (14):

$$
\phi_{\mathrm{f}}=\frac{V_{\mathrm{BN}}}{V_{\mathrm{BN}}+V_{\mathrm{PHBV}}}
$$

In the Halpin-Tsai model, the symbol $\xi$, is defined by the width $(w)$ and thickness $(t)$ of the nanoparticles and is defined by Equation (15):

$$
\xi=2 \frac{w}{t}
$$

Furthermore, from the Hui-Shia model (Equation (4)), the $\xi$ and $\Lambda$ are defined in Equations (11) and (13). Generally, it was reported that the model prediction was in good correlation with the experimental results. However, it was reported from the PHBV/ OSFBN composites that at low contents of the filler $(0.5$ and $1 \mathrm{wt} \%)$ showed higher values than the predicted values of the models (Figure 9), with the models depicting higher values at higher filler loadings. This behavior was ascribed to an overestimation of the reinforcement by models at higher loading which was due to several factors such as agglomeration and inhomogeneity.

Farooq et al. [93] reported on the mechanical properties of the liquid exfoliated and hydroxylated functionalized hexagonal boron nitride nanosheets (h-BNNs-OH) reinforced PMMA composites fabricated by solution mixing method. There was a considerable increase in the ultimate tensile strength
(UTS) of the non-functionalized and functionalized h-BNNs/PMMA composites, with non-functionalized h-BNNS recording a value of $19 \mathrm{MPa}$, while the h-BNNs-OH based composites recorded UTS value of $26 \mathrm{MPa}$, when compared with neat PMMA with UTS value of $15 \mathrm{MPa}$. The enhancement in the UTS was attributed to a better interaction between a filler and PMMA matrix, with functionalized BNNS being able to provide a better interaction in the system; as a result, a higher UTS value is obtained. Ultrasonically exfoliated boron nitride reinforced polylactic acid (PLA) was fabricated by solvent casting process [94] for possible packaging applications. All PLA/BN based composites revealed an improvement in mechanical properties irrespective of the BN content which was ranging from 0 to $4 \mathrm{wt} \%$. The highest value of tensile strength (viz $28.5 \mathrm{MPa}$ ) was reported at $2 \mathrm{wt} \%$ of the BN, which was associated with a better dispersion at this content into the PLA matrix. The associated elastic moduli of the $2 \mathrm{wt} \% \mathrm{BN}$ composites were recorded as $786 \mathrm{MPa}$, which was highest when compared with neat PLA (viz $220 \mathrm{MPa}$ ) and other BN/PLA based composites. Based on the results of tensile strength and elastic moduli it became clear that the optimum concentration of $\mathrm{BN}$ in PLA based composites in relation to mechanical properties was $2 \mathrm{wt} \%$. Furthermore, one can realize that the addition of higher content may have a negative effect on the mechanical integrity of the polymer matrices. Recently, boron nitride hybrid polymer composites have been investigated in order to improve the mechanical properties more than single boron nitride alone. Cui et al. [95] have investigated the effect of synergistic effect between exfoliated boron nitride and graphene nanosheets reinforced polystyrene (PS) and polyamide (PA) on the mechanical
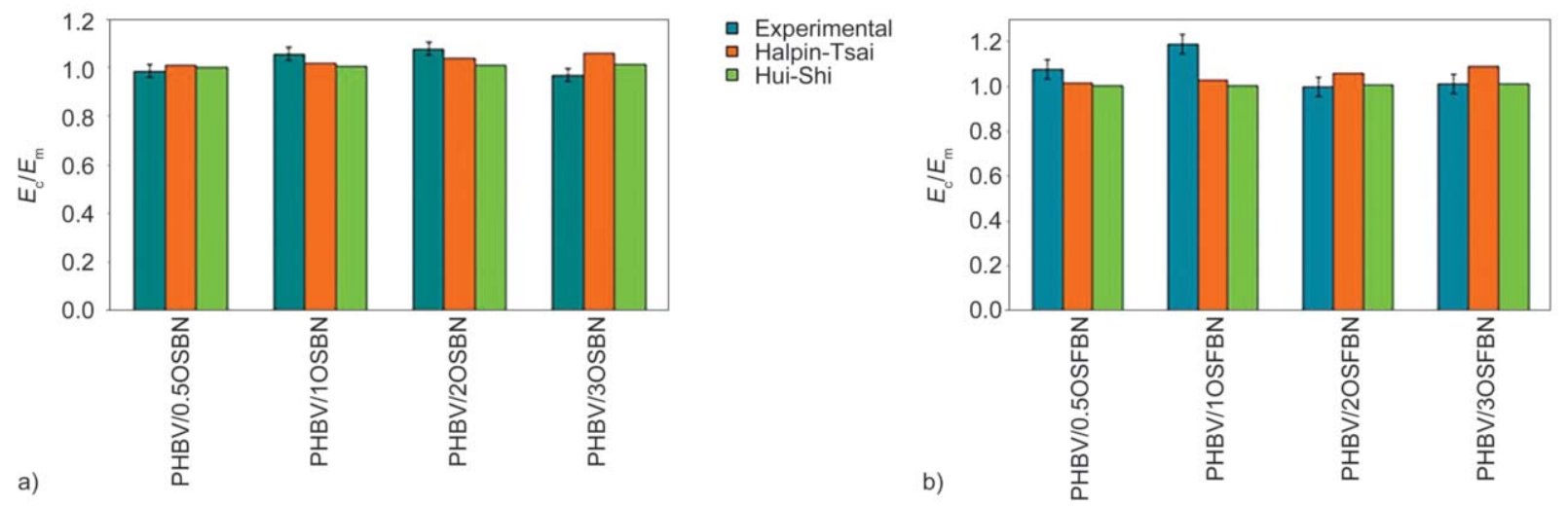

Figure 9. A comparison of the Halpin-Tsai and Hui-Shia models with the experimental results [92] (MDPI open access). 
properties. A few layered boron nitride (s-BN) and graphene (s-GH) composites were prepared by solution blending followed by hot-pressing. Young's modulus and microhardness of the composites were obtained by nanoindentation technique which is utilized to characterize the mechanical properties of materials at small scale. The addition of both fillers enhanced the hardness and Young's modulus $(E)$ of the composites. The composite sample with $20 \mathrm{wt} \%$ of graphene reinforced polystyrene had an $E$ value of $4.7 \mathrm{GPa}$, while the addition of $1.5 \mathrm{wt} \%$ boron nitride enhanced the value to $6.3 \mathrm{GPa}$, which was reported to be $34 \%$ improvement. Furthermore, the addition of $1.5 \mathrm{wt} \% \mathrm{BN}$ enhanced the hardness from 0.2 (PSG20) to $0.25 \mathrm{MPa}$ (PSG20B1.5). The main reason behind an improvement in mechanical properties due to $\mathrm{BN}$ filling in the spaces, i.e., interspaces between the GH sheets, resulted in forming the s-BN/ s-GH stacked structure, which played a key role in improving the properties. In recent years, there have been demands for the fabrication of thermally conductive materials coupled with electrical insulation with exceptional mechanical properties for advanced applications such as the electronic field. Hu et al. [96] fabricated a synergistic effect of positively charged hexagonal boron nitride and silica-coated carbon nanotubes reinforced poly(vinylidene fluoride) (PVDF) composites through the electrostatic repulsion. In this 3D network fabricated composites, positively charged h-boron nitride was co-modified by polydopamine (PDA) and (3-Aminopropyl) trimethoxysilane (APTMS) modifiers. In this study, the role of APTMS was to act as a modifier, thereby offering h-BN positive charge and further enhancing a hydrogen bond in the inorganic filler-polymer matrix interface. In the MWCNTs- $\mathrm{SiO}_{2}$ synergy, $\mathrm{SiO}_{2}$ was employed an electrical insulator layer to hinder the delocalization of the electrons of the MWCNTs. The tensile strength of unmodified h-BN/PVDF composite was less than that of modified hexagonal boron nitride $(\mathrm{m}-\mathrm{hBN})$, with the highest tensile strength being obtained at the sample consisting of $20 \mathrm{wt} \%$ of the $\mathrm{m}-\mathrm{hBN} / \mathrm{MWCNTs}-\mathrm{SiO}_{2}$. The enhancement in tensile strength was ascribed to the high strength and modulus as well as the dimensional stability of h-BN and MWCNTs, which are able to reinforce the matrix and assist the PVDF matrix load bearing. Table 8 summarizes the mechanical properties of selective studies on boron nitride reinforced polymers.

\section{Conclusions}

Different studies have proved that using modified boron nitride fillers tremendously improved thermal conductivity as well as interfacial adhesion between the fillers and polymer matrices. Surface modified BN improves the filler dispersion and reduces filler agglomerates which results in better interfacial interaction between filler and polymer matrices, consequently enhancing the thermal conductivity of the composites. Furthermore, it was shown that the synergistic effect of boron nitride with other conductive fillers improved the thermal conductivity of the composites more than a single $\mathrm{BN}$ incorporated in polymer matrices. It was also apparent that the in-plane orientation of boron nitride and its synergistic effect with other fillers greatly improved the thermal conductivity of the composites as compared to the inplane orientation of fillers. It became evident that increasing the filler content proved to be effective in increasing the thermal conductivity of polymers. Furthermore, the review shows that models such as the Maxwell model, Rayleigh model, McKenzie model, Bruggeman model, Hashin-Shtrikman model, Voigt-Reuss (series and parallel model), modified effective medium approximation (EMA) model, LewisNielsen model, and Agari model have been commonly used to predict the thermal conductivities of $\mathrm{BN}$-polymer composites. However, it has been shown that typical models such as the EMA model tend to underestimate the thermal conductivity of composites where the thermal conductivity of the filler particle is more than that of the matrix. Furthermore, using these models requires the supply of thermal conductivity values for the fillers and other parameters, like the A parameter in the Lewis-Nielsen model. These parameters are quite hard to measure or define, especially for a filler particle such as BN platelets of single or multiple layers. The platelets have complex shapes, and varying thermal conductivity values are found in the literature. Based on the summarised studies in this study, it became clear that there were few biodegradable polymer matrices employed for the fabrication of boron nitride polymer composites. The demand for utilization of eco-friendly products for advanced applications shows there is still a need for researchers to try and prepare more of the boron nitride biopolymer-based composites. There is also a future prospect for the fabrication of more boron nitride-based polymer blend composites, specifically 
Table 8. Mechanical properties of selected BN/polymer composites.

\begin{tabular}{|c|c|c|c|}
\hline BN/polymer composites & Preparation methods & Mechanical properties & References \\
\hline $\begin{array}{l}\text { PA6/BN composites, } \\
\text { PA6 - polyamide } 6 \\
\text { BN - boron nitride }\end{array}$ & $\begin{array}{l}\text { Anionic ring-opening } \\
\text { polymerization }\end{array}$ & $\begin{array}{l}\text { - The Young's modulus and yield strength of PA6/BN composites con- } \\
\text { sisting of functionalized BN (f-BN) were increased with the introduc- } \\
\text { tion of f-BN. However, small fluctuations in Young's modulus and } \\
\text { yield strength were observed in PA6/BN composites consisting of } \\
\text { hexagonal BN (h-BN) at similar BN contents. }\end{array}$ & {$[97]$} \\
\hline $\begin{array}{l}\text { Nylon-6/boron nitride } \\
\text { (BN) polymer composites }\end{array}$ & Injection molding & $\begin{array}{l}\text { - The tensile strength of nylon- } 6 / \mathrm{BN} \text { composites was increased at } 4 \% \\
\text { BN and decreased at } 16 \% \mathrm{BN} \text {. } \\
\text { - The Rockwell hardness value of nylon- } 6 / \mathrm{BN} \text { composites was maxi- } \\
\text { mum at } 12 \% \mathrm{BN} \text { with increasing } \mathrm{BN} \text { content. }\end{array}$ & {$[98]$} \\
\hline $\begin{array}{l}\text { BNF/polyethylene glycol } \\
\text { (PBNF) composites, } \\
\text { BNF - } 3 \text { D boron nitride } \\
\text { framework }\end{array}$ & $\begin{array}{l}\text { Unidirectional freez- } \\
\text { ing technique }\end{array}$ & $\begin{array}{l}\text { - The Young's modulus of the composites was enhanced by } 356 \% \text { with } \\
\text { the addition of BNF. }\end{array}$ & [99] \\
\hline $\begin{array}{l}\text { n-CMBN/PEEK, } \\
\text { n-CMBN - non-covalent } \\
\text { modified boron nitride, } \\
\text { PEEK - poly(ether ether } \\
\text { ketone) }\end{array}$ & $\begin{array}{l}\text { Powder mixing and } \\
\text { melt mixing }\end{array}$ & $\begin{array}{l}\text { - n-CMBN/PEEK composites exhibited a tensile strength and elongation } \\
\text { at break of above } 99.0 \mathrm{MPa} \text { and } 14 \% \text {, respectively. }\end{array}$ & {$[100]$} \\
\hline $\begin{array}{l}\text { PCL/BN composites, } \\
\text { PCL - polycaprolactone }\end{array}$ & $\begin{array}{l}\text { Microwave-assisted } \\
\text { ring-opening polymer- } \\
\text { ization of } \varepsilon \text {-caprolac- } \\
\text { tone }(\varepsilon-C L)\end{array}$ & $\begin{array}{l}\text { - The tensile strength and tensile modulus of PCL/Mbn (hydroxyl func- } \\
\text { tional BN) composites were } 1.58 \text { and } 2.05 \text { times higher than those of } \\
\text { PCL at } 5 \mathrm{wt} \% \text { Mbn. }\end{array}$ & {$[101]$} \\
\hline $\begin{array}{l}\text { Polyethylene terephtha- } \\
\text { late/hexagonal boron ni- } \\
\text { tride nanosheets nano- } \\
\text { composites (PET/BNNs) }\end{array}$ & $\begin{array}{l}\text { Solution casting } \\
\text { method }\end{array}$ & $\begin{array}{l}\text { - The composites exhibited a } 33.3 \text { and } 32.4 \% \text { increase in elastic modulus } \\
\text { and hardness with the incorporation of } 2 \mathrm{wt} \% \text { BNNs. }\end{array}$ & {$[102]$} \\
\hline $\begin{array}{l}\text { BN/polyurethane@poly- } \\
\text { dopamine } \\
\text { (PU@PDA)/polyethylene } \\
\text { glycol (PEG) (PBPP) }\end{array}$ & $\begin{array}{l}\text { Surface treating and } \\
\text { water-based dip-coat- } \\
\text { ing procedure fol- } \\
\text { lowed by vacuum in- } \\
\text { filtration technology. }\end{array}$ & $\begin{array}{l}\text { - The mechanical properties of the composites were nearly four times } \\
\text { higher than those of neat PEG. }\end{array}$ & [103] \\
\hline $\begin{array}{l}\text { Polycarbonate/boron ni- } \\
\text { tride (PC/BN) composites }\end{array}$ & $\begin{array}{l}\text { Masterbatch dilution } \\
\text { and direct mixing }\end{array}$ & $\begin{array}{l}\text { - The tensile properties of } \mathrm{PC} / \mathrm{BN} \text { composites prepared by masterbatch } \\
\text { dilution were higher than those of } \mathrm{PC} / \mathrm{BN} \text { composites prepared by di- } \\
\text { rect mixing when the filler loading was less than } 30 \mathrm{wt} \% \text {. }\end{array}$ & {$[104]$} \\
\hline $\begin{array}{l}\text { MXene/PSZ-ABN com- } \\
\text { posite films, } \\
\text { PSZ-ABN - polysilazane } \\
\text { (PSZ) - coated aggregat- } \\
\text { ed boron nitride (ABN), } \\
\text { Mxene - } \mathrm{TiCl}_{3} \text { Mxene }\end{array}$ & Hot pressing & $\begin{array}{l}\text { - The incorporation of Mxene increased the tensile properties of the } \\
\text { composite films from } 4.22 \text { to } 11.96 \mathrm{MPa} \text {. }\end{array}$ & {$[105]$} \\
\hline
\end{tabular}

with the localization of the boron nitride within one of the polymers in the blends. The addition of $\mathrm{BN}$ into polymer blends as a third component might also explore the possibility of BN as a compatibilizer between the blend(s). Furthermore, there have been a few studies on the effect of boron nitride geometry on the thermal conductivity of boron nitride-polymer composites. The geometry of boron nitride fillers seems to influence the thermally conductive pathways of conductive polymer composites; therefore, more work needs to be done to investigate this aspect.

\section{Acknowledgements}

The authors would like to acknowledge the National Research Foundation (NRF) of South Africa.

\section{References}

[1] An D., Cheng S., Jiang C., Duan X., Yang B., Zhang Z., Li J., Liu Y., Wong C-P.: A novel environmentally friendly boron nitride/lignosulfonate/natural rubber composite with improved thermal conductivity. Journal of Materials Chemistry C, 8, 4801-4809 (2020). https://doi.org/10.1039/C9TC05699H 
[2] Zhou T., Smith M. K., Berenguer J. P., Quill T. J., Cola B. A., Kalaitzidou K., Bougher T. L.: The impact of polymer matrix blends on thermal and mechanical properties of boron nitride composites. Journal of Applied Polymer Science, 137, 48661/1-48661/6 (2020). https://doi.org/10.1002/app.48661

[3] Leung S. N.: Thermally conductive polymer composites and nanocomposites: Processing-structure-property relationships. Composites Part B: Engineering, 150, 78-92 (2018).

https://doi.org/10.1016/j.compositesb.2018.05.056

[4] Tang Y., Xiao C., Ding J., Hu K., Zeng K., Tian X.: Synergetic enhancement of thermal conductivity in the silica-coated boron nitride $\left(\mathrm{SiO}_{2} @ \mathrm{BN}\right) /$ polymethyl methacrylate (PMMA) composites. Colloid and Polymer Science, 298, 385-393 (2020).

https://doi.org/10.1007/s00396-020-04617-4

[5] Ngo I-L., Jeon S., Byon C.: Thermal conductivity of transparent and flexible polymers containing fillers: A literature review. International Journal of Heat and Mass Transfer, 98, 219-226 (2016). https://doi.org/10.1016/j.ijheatmasstransfer.2016.02.082

[6] Zha X-J., Yang J., Pu J-H., Feng C-P., Bai L., Bao R-Y., Liu Z-Y., Yang M-B., Yang W.: Enhanced thermal conductivity and balanced mechanical performance of $\mathrm{PP} / \mathrm{BN}$ composites with $1 \mathrm{vol} \%$ finely dispersed MWCNTs assisted by OBC. Advanced Materials Interfaces, 6, 1900081/1-1900081/7 (2019). https://doi.org/10.1002/admi.201900081

[7] Chung S-L., Lin J-S.: Thermal conductivity of epoxy resin composites filled with combustion synthesized h-BN particles. Molecules, 21, 670/1-670/11 (2016). https://doi.org/10.3390/molecules21050670

[8] Harada M., Hamaura N., Ochi M., Agari Y.: Thermal conductivity of liquid crystalline epoxy/BN filler composites having ordered network structure. Composites Part B: Engineering, 55, 306-313 (2013). https://doi.org/10.1016/j.compositesb.2013.06.031

[9] Wu X., Liu W., Ren L., Zhang C.: Highly thermally conductive boron nitride@UHMWPE composites with segregated structure. e-Polymers, 20, 510-518 (2020). https://doi.org/10.1515/epoly-2020-0053

[10] Joy J., George E., Haritha P., Thomas S., Anas S.: An overview of boron nitride based polymer nanocomposites. Journal of Polymer Science, 58, 3115-3141 (2020). https://doi.org/10.1002/pol.20200507

[11] Hussain A. R. J., Alahyari A. A., Eastman S. A., Thibaud-Erkey C., Johnston S., Sobkowicz M. J.: Review of polymers for heat exchanger applications: Factors concerning thermal conductivity. Applied Thermal Engineering, 113, 1118-1127 (2017). https://doi.org/10.1016/j.applthermaleng.2016.11.041

[12] Zhang Y., Heo Y-J., Son Y-R., In I., An K-H., Kim B-J., Park S-J.: Recent advanced thermal interfacial materials: A review of conducting mechanisms and parameters of carbon materials. Carbon, 142, 445-460 (2019). https://doi.org/10.1016/j.carbon.2018.10.077
[13] Xu Y., Chung D. D. L.: Increasing the thermal conductivity of boron nitride and aluminum nitride particle epoxy-matrix composites by particle surface treatments. Composite Interfaces, 7, 243-256 (2000). https://doi.org/10.1163/156855400750244969

[14] Zhang X., Wu H., Guo S.: Effect of interfacial interaction on morphology and properties of polyethylene/ boron nitride thermally conductive composites. Polymer-Plastics Technology and Engineering, 54, 10971105 (2015). https://doi.org/10.1080/03602559.2014.974280

[15] Golberg D., Bando Y., Huang Y., Xu Z., Wei X., Bourgeois L., Wang M-S., Zeng H., Lin J., Zhi C.: Recent advances in boron nitride nanotubes and nanosheets. Israel Journal of Chemistry, 50, 405-416 (2010). https://doi.org/10.1002/ijch.201000049

[16] Yu C., Zhang J., Tian W., Fan X., Yao Y.: Polymer composites based on hexagonal boron nitride and their application in thermally conductive composites. RSC Advances, 8, 21948-21967 (2018). https://doi.org/10.1039/C8RA02685H

[17] Nakano S., Fukunaga O.: New scope of high pressurehigh temperature synthesis of cubic boron nitride. Diamond and Related Materials, 2, 1409-1413 (1993). https://doi.org/10.1016/0925-9635(93)90149-V

[18] Du M., Wu Y., Hao X.: A facile chemical exfoliation method to obtain large size boron nitride nanosheets. CrystEngComm, 15, 1782-1786 (2013). https://doi.org/10.1039/C2CE26446C

[19] Lin J., Xu L., Huang Y., Li J., Wang W., Feng C., Liu Z., Xu X., Zou J., Tang C.: Ultrafine porous boron nitride nanofibers synthesized via a freeze-drying and pyrolysis process and their adsorption properties. RSC Advances, 6, 1253-1259 (2016). https://doi.org/10.1039/C5RA23426C

[20] Han R., Khan M. H., Angeloski A., Casillas G., Yoon C. W., Sun X., Huang Z.: Hexagonal boron nitride nanosheets grown via chemical vapor deposition for silver protection. ACS Applied Nano Materials, 2, 28302835 (2019).

https://doi.org/10.1021/acsanm.9b00298

[21] Li L. H., Chen Y., Glushenkov A. M.: Synthesis of boron nitride nanotubes by boron ink annealing. Nanotechnology, 21, 105601/1-105601/5 (2010). https://doi.org/10.1088/0957-4484/21/10/105601

[22] Seyhan A. T., Göncü Y., Durukan O., Akay A., Ay N.: Silanization of boron nitride nanosheets (BNNSs) through microfluidization and their use for producing thermally conductive and electrically insulating polymer nanocomposites. Journal of Solid State Chemistry, 249, 98-107 (2017). https://doi.org/10.1016/j.jssc.2017.02.020

[23] Wang S., Tao B., Yu S., Wei C., Zhou T., Chen X., Han C., Wang C.: Insight into the liquid-phase exfoliation to prepare BN nanosheets. Materials Letters, 269, 127644/1-127644/4 (2020). https://doi.org/10.1016/j.matlet.2020.127644 
[24] Liu J., Kutty R. G., Liu Z.: Controlled synthesis of atomically layered hexagonal boron nitride via chemical vapor deposition. Molecules, 21, 1636/1-1636/8 (2016). https://doi.org/10.3390/molecules21121636

[25] Pandit S., Gaska K., Mokkapati V. R. S. S., Forsberg S., Svensson M., Kádár R., Mijakovic I.: Antibacterial effect of boron nitride flakes with controlled orientation in polymer composites. RSC Advances, 9, 3345433459 (2019). https://oi.org/10.1039/C9RA06773F

[26] Yadav V., Kulshrestha V.: Boron nitride: A promising material for proton exchange membranes for energy applications. Nanoscale, 11, 12755-12773 (2019). https://doi.org/10.1039/C9NR03094H

[27] Jiang X-F., Weng Q., Wang X-B., Li X., Zhang J., Golberg D., Bando Y.: Recent progress on fabrications and applications of boron nitride nanomaterials: A review. Journal of Materials Science and Technology, 31, 589-598 (2015).

https://doi.org/10.1016/j.jmst.2014.12.008

[28] Samantaray C. B., Singh R. N.: Review of synthesis and properties of cubic boron nitride (c-BN) thin films. International Materials Reviews, 50, 313-344 (2005). https://doi.org/10.1179/174328005X67160

[29] Du B. X., Cui B.: Effects of thermal conductivity on dielectric breakdown of micro, nano sized BN filled polypropylene composites. IEEE Transactions on Dielectrics and Electrical Insulation, 23, 2116-2125 (2016). https://doi.org/10.1109/TDEI.2016.7556486

[30] Yu Z., Wang X., Bian H., Jiao L., Wu W., Dai H.: Enhancement of the heat conduction performance of boron nitride/cellulosic fibre insulating composites. Plos One, 13, e0200842/1-e0200842/10 (2018). https://doi.org/10.1371/journal.pone.0200842

[31] Ayoob R., Alhabill F., Andritsch T., Vaughan A.: Enhanced dielectric properties of polyethylene/hexagonal boron nitride nanocomposites. Journal of Materials Science, 53, 3427-3442 (2018). https://doi.org/10.1007/s10853-017-1786-y

[32] Wie J., Kim J.: Thermal properties of binary filler hybrid composite with graphene oxide and pyrolyzed silicon-coated boron nitride. Polymers, 12, 2553/1-2553/9 (2020). https://doi.org/10.3390/polym12112553

[33] Yang S-Y., Huang Y-F., Lei J., Zhu L., Li Z-M.: Enhanced thermal conductivity of polyethylene/boron nitride multilayer sheets through annealing. Composites Part A: Applied Science and Manufacturing, 107, 135143 (2018).

https://doi.org/10.1016/j.compositesa.2017.12.031
[34] Zhong S-L., Zhou Z-Y., Zhang K., Shi Y-D., Chen Y-F., Chen X-D., Zeng J-B. Wang M.: Formation of thermally conductive networks in isotactic polypropylene/hexagonal boron nitride composites via 'bridge effect' of multi-wall carbon nanotubes and graphene nanoplatelets. RSC Advances, 6, 98571-98580 (2016). https://doi.org/10.1039/C6RA24046A

[35] Weng L., Wang H., Zhang X., Liu L., Zhang H.: Preparation and properties of boron nitride/epoxy composites with high thermal conductivity and electrical insulation. Journal of Materials Science: Materials in Electronics, 29, 14267-14276 (2018).

https://doi.org/10.1007/s10854-018-9560-8

[36] Jing L., Li H., Tay R.Y., Sun B., Tsang S. H., Cometto O., Lin J., Teo E. H. T., Tok A I. Y.: Biocompatible hydroxylated boron nitride nanosheets/poly(vinyl alcohol) interpenetrating hydrogels with enhanced mechanical and thermal responses. ACS Nano, 11, 37423751 (2017).

https://doi.org/10.1021/acsnano.6b08408

[37] Fei T., Li Y., Liu B., Xia C.: Flexible polyurethane/boron nitride composites with enhanced thermal conductivity. High Performance Polymers, 32, 324-333 (2020). https://doi.org/10.1177/0954008319862044

[38] Hu Z., Wang S., Liu Y., Qu Z., Tan Z., Wu K., Shi J., Liang L., Lu M.: Constructing a layer-by-layer architecture to prepare a transparent, strong, and thermally conductive boron nitride nanosheet/cellulose nanofiber multilayer film. Industrial and Engineering Chemistry Research, 59, 4437-4446 (2020).

https://doi.org/10.1021/acs.iecr.9b05602

[39] Huang X., Wang S., Zhu M., Yang K., Jiang P., Bando Y., Golberg D., Zhi C.: Thermally conductive, electrically insulating and melt-processable polystyrene/boron nitride nanocomposites prepared by in situ reversible addition fragmentation chain transfer polymerization. Nanotechnology, 26, 015705/1-015705/10 (2014). https://doi.org/10.1088/0957-4484/26/1/015705

[40] Duan Z-Q., Zhong M., Shi F-K., Xie X-M.: Transparent $h$-BN/polyacrylamide nanocomposite hydrogels with enhanced mechanical properties. Chinese Chemical Letters, 27, 1490-1494 (2016). https://doi.org/10.1016/j.cclet.2016.04.002

[41] Decol M., Pachekoski W. M., Becker D.: Enhancing thermal conductivity and near-infrared radiation reflectance of poly( $\varepsilon$-caprolactone)/poly(lactic acid)based nanocomposites by incorporating hexagonal boron nitride. Polymer Composites, 40, 3464-3471 (2019). https://doi.org/10.1002/pc.25208

[42] Madakbaş S., Çakmakçı E., Kahraman M. V.: Preparation and thermal properties of polyacrylonitrile/hexagonal boron nitride composites. Thermochimica Acta, 552, 1-4 (2013). https://doi.org/10.1016/j.tca.2012.11.011 
[43] Li G., Xing R., Geng P., Liu Z., He L., Wang N., Zhang Q., Qu X.: Surface modification of boron nitride via poly(dopamine) coating and preparation of acrylonitrile-butadiene-styrene copolymer/boron nitride composites with enhanced thermal conductivity. Polymers for Advanced Technologies, 29, 337-346 (2018). https://doi.org/10.1002/pat.4119

[44] Qu T., Yang N., Hou J., Li G., Yao Y., Zhang Q., He L., Wu D., Qu X.: Flame retarding epoxy composites with poly(phosphazene-co-bisphenol A)-coated boron nitride to improve thermal conductivity and thermal stability. RSC Advances, 7, 6140-6151 (2017). https://doi.org/10.1039/C6RA27062J

[45] Li T-L., Hsu S. L-C.: Enhanced thermal conductivity of polyimide films via a hybrid of micro- and nanosized boron nitride. The Journal of Physical Chemistry B, 114, 6825-6829 (2010). https://doi.org/10.1021/jp101857w

[46] Yan W., Zhang Y., Sun H., Liu S., Chi Z., Chen X., Xu J.: Polyimide nanocomposites with boron nitride-coated multi-walled carbon nanotubes for enhanced thermal conductivity and electrical insulation. Journal of Materials Chemistry A, 2, 20958-20965 (2014). https://doi.org/10.1039/C4TA04663C

[47] Zhao C. B., Xu S. C., Qin Y. F., Su L., Yang X. J.: Thermal conductivity cyanate ester resin composites filled with boron nitride. Advanced Materials Research, 893, 259-262 (2014). https://doi.org/10.4028/www.scientific.net/AMR.893.259

[48] Chen H., Ginzburg V. V., Yang J., Yang Y., Liu W., Huang Y., Du L., Chen B.: Thermal conductivity of polymer-based composites: Fundamentals and applications. Progress in Polymer Science, 59, 41-85 (2016). https://doi.org/10.1016/j.progpolymsci.2016.03.001

[49] Zeng H., Wu J., Pei H., Zhang Y., Ye Y., Liao Y., Xie X.: Highly thermally conductive yet mechanically robust composites with nacre-mimetic structure prepared by evaporation-induced self-assembly approach. Chemical Engineering Journal, 405, 126865/1-126865/13 (2021) https://doi.org/10.1016/j.cej.2020.126865

[50] Zheng Z., Cox M., Li B.: Surface modification of hexagonal boron nitride nanomaterials: A review. Journal of Materials Science, 53, 66-99 (2018). https://doi.org/10.1007/s10853-017-1472-0

[51] Kausar A.: Thermally conducting polymer/nanocarbon and polymer/inorganic nanoparticle nanocomposite: A review. Polymer-Plastics Technology and Materials, 59, 895-909 (2020). https://doi.org/10.1080/25740881.2019.1708103

[52] Wie J., Kim K., Kim J.: High thermal conductivity composites obtained by novel surface treatment of boron nitride. Ceramics International, 46, 17614-17620 (2020)

https://doi.org/10.1016/j.ceramint.2020.04.063
[53] Ahn K., Kim K., Kim J.: Fabrication of surface-treated BN/ETDS composites for enhanced thermal and mechanical properties. Ceramics International, 41, 94889495 (2015).

https://doi.org/10.1016/j.ceramint.2015.04.006

[54] Lule Z., Kim J.: Surface modification of aluminum nitride to fabricate thermally conductive poly(butylene succinate) nanocomposite. Polymers, 11, 148/1-148/15 (2019). https://doi.org/10.3390/polym11010148

[55] Hayward M. R., Johnston J. H., Dougherty T., de Silva K.: Interfacial adhesion: Improving the mechanical properties of silicon nitride fibre - epoxy polymer composites. Composite Interfaces, 26, 263-273 (2019). https://doi.org/10.1080/09276440.2018.1499328

[56] Lee W., Kim J.: Enhanced through-plane thermal conductivity of paper-like cellulose film with treated hybrid fillers comprising boron nitride and aluminum nitride. Composites Science and Technology, 200, 108424/1-108424/8 (2020).

https://doi.org/10.1016/j.compscitech.2020.108424

[57] Pan C., Kou K., Jia Q., Zhang Y., Wu G., Ji T.: Improved thermal conductivity and dielectric properties of h-BN/PTFE composites via surface treatment by silane coupling agent. Composites Part B: Engineering, 111, 83-90 (2017).

https://doi.org/10.1016/j.compositesb.2016.11.050

[58] Guo Y., Lyu Z., Yang X., Lu Y., Ruan K., Wu Y., Kong J., Gu J.: Enhanced thermal conductivities and decreased thermal resistances of functionalized boron nitride/polyimide composites. Composites Part B: Engineering, 164, 732-739 (2019).

https://doi.org/10.1016/j.compositesb.2019.01.099

[59] Yang X., Yu X., Naito K., Ding H., Qu X., Zhang Q.: Enhanced thermal conductivity of polyimide composites filled with modified h-BN and nanodiamond hybrid filler. Journal of Nanoscience and Nanotechnology, 18, 3291-3298 (2018). https://doi.org/10.1166/jnn.2018.14630

[60] Borjas-Ramos J. J., Ramos-de-Valle L. F., NeiraVelázquez M. G., Hernández-Hernández E., SaucedoSalazar E. M., Soria-Argüello G.: Thermal conductivity of nanocomposites based in high density polyethylene and surface modified hexagonal boron nitride via cold ethylene plasma. Plasma Chemistry and Plasma Processing, 38, 429-441 (2018). https://doi.org/10.1007/s11090-017-9864-0

[61] Yang H., Chen Q., Wang X., Chi M., Liu H., Ning X.: Dielectric and thermal conductivity of epoxy resin impregnated nano-h-BN modified insulating paper. Polymers, 11, 1359/1-1359/13 (2019).

https://doi.org/10.3390/polym11081359

[62] Feng M., Pan Y., Zhang M., Gao Q., Liu C., Shen C., Liu X.: Largely improved thermal conductivity of HDPE composites by building a 3D hybrid fillers network. Composites Science and Technology, 206, 108666 (2021).

https://doi.org/10.1016/j.compscitech.2021.108666 
[63] Ren P-G., Si X-H., Sun Z-F., Ren F., Pei L., Hou S-Y.: Synergistic effect of BN and MWCNT hybrid fillers on thermal conductivity and thermal stability of ultrahigh-molecular-weight polyethylene composites with a segregated structure. Journal of Polymer Research, 23, 21/1-21/11 (2016). https://doi.org/10.1007/s10965-015-0908-y

[64] Wang Z-G., Gong F., Yu W-C., Huang Y-F., Zhu L., Lei J., Xu J-Z., Li Z-M.: Synergetic enhancement of thermal conductivity by constructing hybrid conductive network in the segregated polymer composites. Composites Science and Technology, 162, 7-13 (2018). https://doi.org/10.1016/j.compscitech.2018.03.016

[65] Che J., Jing M., Liu D., Wang K., Fu Q.: Largely enhanced thermal conductivity of HDPE/boron nitride/ carbon nanotubes ternary composites via filler networknetwork synergy and orientation. Composites Part A: Applied Science and Manufacturing, 112, 32-39 (2018). https://doi.org/10.1016/j.compositesa.2018.05.016

[66] Song H., Kim B. G., Kim Y. S., Bae Y-S., Kim J., Yoo Y.: Synergistic effects of various ceramic fillers on thermally conductive polyimide composite films and their model predictions. Polymers, 11, 484/1-484/9 (2019). https://doi.org/10.3390/polym11030484

[67] Guo Y., Ruan K., Shi X., Yang X., Gu J.: Factors affecting thermal conductivities of the polymers and polymer composites: A review. Composites Science and Technology, 193, 108134/1-108134/25 (2020). https://doi.org/10.1016/j.compscitech.2020.108134

[68] Fu C., Li Q., Lu J., Mateti S., Cai Q., Zeng X., Du G., Sun R., Chen Y., Xu J., Wong C-P.: Improving thermal conductivity of polymer composites by reducing interfacial thermal resistance between boron nitride nanotubes. Composites Science and Technology, 165, 322330 (2018).

https://doi.org/10.1016/j.compscitech.2018.07.010

[69] Jiang F., Cui X., Song N., Shi L., Ding P.: Synergistic effect of functionalized graphene/boron nitride on the thermal conductivity of polystyrene composites. Composites Communications, 20, 100350/1-100350/6 (2020) https://doi.org/10.1016/j.coco.2020.04.016

[70] Yang J., Tang L-S., Bao R-Y., Bai L., Liu Z-Y., Yang W., Xie B-H., Yang M-B.: Largely enhanced thermal conductivity of poly(ethylene glycol)/boron nitride composite phase change materials for solar-thermal-electric energy conversion and storage with very low content of graphene nanoplatelets. Chemical Engineering Journal, 315, 481-490 (2017).

https://doi.org/10.1016/j.cej.2017.01.045

[71] Wu Y., Zhang X., Negi A., He J., Hu G., Tian S., Liu J.: Synergistic effects of boron nitride $(\mathrm{BN})$ nanosheets and silver (Ag) nanoparticles on thermal conductivity and electrical properties of epoxy nanocomposites. Polymers, 12, 426/1-426/13 (2020). https://doi.org/10.3390/polym12020426
[72] Zhang D-L., Liu S-N., Cai H-W., Feng Q-K., Zhong S. L., Zha J. W., Dang Z. M.: Enhanced thermal conductivity and dielectric properties in electrostatic selfassembly 3D pBN@nCNTs fillers loaded in epoxy resin composites. Journal of Materiomics, 6, 751-759 (2020). https://doi.org/10.1016/j.jmat.2020.06.013

[73] Cai X., Dong X., Lv W., Ji C., Jiang Z., Zhang X., Gao T., Yue K., Zhang X.: Synergistic enhancement of thermal conductivity for low dielectric constant boron nitride-polytetrafluoroethylene composites by adding small content of graphene nanosheets. Composites Communications, 17, 163-169 (2020).

https://doi.org/10.1016/j.coco.2019.12.002

[74] Wu Y., Zhang X., Hu G.: Thermal and mechanical properties study of boron nitride nanosheets decorated by silver/epoxy nanocomposites. SN Applied Sciences, 2, 770/1-770/8 (2020). https://doi.org/10.1007/s42452-020-2505-x

[75] Kim K., Kim J.: BN-MWCNT/PPS core-shell structured composite for high thermal conductivity with electrical insulating via particle coating. Polymer, 101, 168-175 (2016). https://doi.org/10.1016/j.polymer.2016.08.062

[76] Bian W., Yao T., Chen M., Zhang C., Shao T., Yang Y.: The synergistic effects of the micro-BN and nano$\mathrm{Al}_{2} \mathrm{O}_{3}$ in micro-nano composites on enhancing the thermal conductivity for insulating epoxy resin. Composites Science and Technology, 168, 420-428 (2018). https://doi.org/10.1016/j.compscitech.2018.10.002

[77] Liang D., Ren P., Ren F., Jin Y., Wang J., Feng C., Duan Q.: Synergetic enhancement of thermal conductivity by constructing $\mathrm{BN}$ and AlN hybrid network in epoxy matrix. Journal of Polymer Research, 27, 212/1212/12 (2020).

https://doi.org/10.1007/s10965-020-02193-3

[78] Zhang J., Lei W., Liu D., Wang X.: Synergistic influence from the hybridization of boron nitride and graphene oxide nanosheets on the thermal conductivity and mechanical properties of polymer nanocomposites. Composites Science and Technology, 151, 252257 (2017).

https://doi.org/10.1016/j.compscitech.2017.08.033

[79] Liu M., Chiang S-W., Chu X., Li J., Gan L., He Y., Li B., Kang F., Du H.: Polymer composites with enhanced thermal conductivity via oriented boron nitride and alumina hybrid fillers assisted by 3 -D printing. Ceramics International, 46, 20810-20818 (2020). https://doi.org/10.1016/j.ceramint.2020.05.096

[80] Xue Y., Li X., Wang H., Zhao F., Zhang D., Chen Y.: Improvement in thermal conductivity of through-plane aligned boron nitride/silicone rubber composites. Materials and Design, 165, 107580/1-107580/8 (2019). https://doi.org/10.1016/j.matdes.2018.107580 
[81] Cao L., Wang J., Dong J., Zhao X., Li H-B., Zhang Q.: Preparation of highly thermally conductive and electrically insulating PI/BNNSs nanocomposites by hotpressing self-assembled PI/BNNSs microspheres. Composites Part B: Engineering, 188, 107882/1-107882/10 (2020).

https://doi.org/10.1016/j.compositesb.2020.107882

[82] Chen L., Xiao C., Tang Y., Zhang X., Zheng K., Tian $\mathrm{X}$.: Preparation and properties of boron nitride nanosheets/cellulose nanofiber shear-oriented films with high thermal conductivity. Ceramics International, 45, 12965-12974 (2019).

https://doi.org/10.1016/j.ceramint.2019.03.224

[83] Kim K., Kim J.: Vertical filler alignment of boron nitride/epoxy composite for thermal conductivity enhancement via external magnetic field. International Journal of Thermal Sciences, 100, 29-36 (2016). https://doi.org/10.1016/j.ijthermalsci.2015.09.013

[84] Pan C., Zhang J., Kou K., Zhang Y., Wu G.: Investigation of the through-plane thermal conductivity of polymer composites with in-plane oriented hexagonal boron nitride. International Journal of Heat and Mass Transfer, 120, 1-8 (2018). https://doi.org/10.1016/j.ijheatmasstransfer.2017.12.015

[85] Chen L., Sun Y-Y., Xu H-F., He S-J., Wei G-S., Du X-Z., Lin J.: Analytic modeling for the anisotropic thermal conductivity of polymer composites containing aligned hexagonal boron nitride. Composites Science and Technology, 122, 42-49 (2016).

https://doi.org/10.1016/j.compscitech.2015.11.013

[86] Goldin N., Dodiuk H., Lewitus D.: Enhanced thermal conductivity of photopolymerizable composites using surface modified hexagonal boron nitride fillers. Composites Science and Technology, 152, 36-45 (2017). https://doi.org/10.1016/j.compscitech.2017.09.001

[87] Ren J., Li Q., Yan L., Jia L., Huang X., Zhao L., Ran Q., Fu M.: Enhanced thermal conductivity of epoxy composites by introducing graphene@boron nitride nanosheets hybrid nanoparticles. Materials and Design, 191, 108663/1-108663/10 (2020).

https://doi.org/10.1016/j.matdes.2020.108663

[88] Kochetov R., Korobko A. V., Andritsch T., Morshuis P. H. F., Picken S. J., Smit J. J.: Three-phase LewisNielsen model for the thermal conductivity of polymer nanocomposites. In 2011 Annual Report Conference on Electrical Insulation and Dielectric Phenomena, IEEE, 338-341 (2011). https://doi.org/10.1109/CEIDP.2011.6232665

[89] Standau T., Pospiech D., Pötschke P., Kretzschmar B., Vogel R., Häußler L., Harre K., Koutsoumpis S., Pissis P., Logakis E.: Preparation and properties of thermally conductive polypropylene composites. Journal of Plastics Technology, 12, 465-495 (2016).

https://doi.org/10.3139/0999.020616
[90] Chen L., Xu H-F., He S-J., Du Y-H., Yu N-J., Du X-Z., Lin J., Nazarenko S.: Thermal conductivity performance of polypropylene composites filled with polydopamine-functionalized hexagonal boron nitride. PloS ONE, 12, e0170523/1-e0170523/16 (2017). https://doi.org/10.1371/journal.pone.0170523

[91] Mai V-D., Lee D-I., Park J-H., Lee D-S.: Rheological properties and thermal conductivity of epoxy resins filled with a mixture of alumina and boron nitride. Polymers, 11, 597/1-597/11 (2019).

https://doi.org/10.3390/polym11040597

[92] Öner M., Kiz1l G., Keskin G., Pochat-Bohatier C., Bechelany M.: The effect of boron nitride on the thermal and mechanical properties of poly(3-hydroxybutyrate-co-3-hydroxyvalerate). Nanomaterials, 8, 940/1940/20 (2018).

https://doi.org/10.3390/nano8110940

[93] Farooq M. U., Jan R., Azeem M., Umer M. A., Akram M. A., Khan A. N., Ahmad I., Khan S. A., Umar Z. A., Liaqat U.: Enhanced mechanical properties of functionalized BN nanosheets-polymer composites. Journal of Polymer Research, 27, 310/1-310/9 (2020). https://doi.org/10.1007/s10965-020-02286-Z

[94] Bindhu B., Renisha R., Roberts L., Varghese T. O.: Boron nitride reinforced polylactic acid composites film for packaging: Preparation and properties. Polymer Testing, 66, 172-177 (2018).

https://doi.org/10.1016/j.polymertesting.2018.01.018

[95] Cui X., Ding P., Zhuang N., Shi L., Song N., Tang S.: Thermal conductive and mechanical properties of polymeric composites based on solution-exfoliated boron nitride and graphene nanosheets: A morphology-promoted synergistic effect. Applied Materials and Interfaces, 7, 19068-19075 (2015).

https://doi.org/10.1021/acsami.5b04444

[96] Hu B., Guo H., Wang Q., Zhang W., Song S., Li X., Li Y., Li B.: Enhanced thermal conductivity by constructing 3D-networks in poly(vinylidene fluoride) composites via positively charged hexagonal boron nitride and silica coated carbon nanotubes. Composites Part A: Applied Science and Manufacturing, 137, 106038/1106038/9 (2020).

https://doi.org/10.1016/j.compositesa.2020.106038

[97] Fang H., Li D., Wu F., Peng X., Chen A., Zhang L., Chen S.: In situ polymerization of polyamide 6/boron nitride composites to enhance thermal conductivity and mechanical properties via boron nitride covalently grafted polyamide 6 . Polymer Engineering and Science, 60, 710-716 (2020).

https://doi.org/10.1002/pen.25329

[98] Kumar K. S., Reddy A. C.: Investigation on mechanical properties and wear performance of nylon-6/boron nitride polymer composites by using Taguchi technique. Results in Materials, 5, 100070/1-100070/5 (2020).

https://doi.org/10.1016/j.rinma.2020.100070 
[99] Jiang F., Song N., Ouyang R., Ding P.: Wall densitycontrolled thermal conductive and mechanical properties of three-dimensional vertically aligned boron nitride network-based polymeric composites. ACS Applied Materials and Interfaces, 13, 7556-7566 (2021). https://doi.org/10.1021/acsami.0c22702

[100] Liu X., Gao Y., Shang Y., Zhu X., Jiang Z., Zhou C., Han J., Zhang H.: Non-covalent modification of boron nitride nanoparticle-reinforced PEEK composite: Thermally conductive, interfacial, and mechanical properties. Polymer, 203, 122763/1-122763/8 (2020). https://doi.org/10.1016/j.polymer.2020.122763

[101] Tian H., Wu F., Chen P., Peng X., Fang H.: Microwave-assisted in situ polymerization of polycaprolactone/boron nitride composites with enhanced thermal conductivity and mechanical properties. Polymer International, 69, 635-643 (2020).

https://doi.org/10.1002/pi.6000

[102] Sahoo A., Gayathri H. N., Sai T. P., Upasani P. S., Raje V., Berkmans J., Ghosh A.: Enhancement of thermal and mechanical properties of few layer boron nitride reinforced PET composite. Nanotechnology, 31, 315706/1-315706/9 (2020). https://doi.org/10.1088/1361-6528/ab88ec
[103] Jiang F., Zhou S., Xu T., Song N., Ding P.: Enhanced thermal conductive and mechanical properties of thermoresponsive polymeric composites: Influence of 3D interconnected boron nitride network supported by polyurethane@polydopamine skeleton. Composites Science and Technology, 208, 108779/1-108779/8 (2021). https://doi.org/10.1016/j.compscitech.2021.108779

[104] Zhou S., Shi Y., Bai Y., Liang M., Zou H.: Preparation of thermally conductive polycarbonate/boron nitride composites with balanced mechanical properties. Polymer Composites, 41, 5418-5427 (2020). https://doi.org/10.1002/pc.25805

[105] Lee S., Kim J.: Incorporating MXene into boron nitride/poly(vinyl alcohol) composite films to enhance thermal and mechanical properties. Polymers, 13, 379/1379/11 (2021).

https://doi.org/10.3390/polym13030379 